\title{
Gene Expression Profile and Signaling Pathways in MCF-7 Breast Cancer Cells Mediated by Acyl-CoA Synthetase 4 Overexpression
}

\section{Ana F Castillo\#, Ulises D Orlando\#, Paula Lopez, Angela R Solano, Paula M. Maloberti and Ernesto J Podesta*}

Biomedical Research Institute, Inbiomed, Department of Biochemistry, School of Medicine University of Buenos Aires, CABA, C1121ABG, Argentina \#equally Contributed

\section{Abstract}

Aim: Breast cancer comprises a heterogeneous group of diseases that vary in morphology, biology, behavior and response to therapy. Previous studies have identified an acyl-CoA synthetase 4 (ACSL4) gene-expression pattern correlated with very aggressive tumors. In particular, we have used the tetracycline Tet-Off system to stably transfect non-aggressive breast cancer MCF-7 cells and developed a stable line overexpressing ACSL4 (MCF-7 Tet-Off/ACSL4). As a result, we have proven that cell transfection solely with ACSL4 CDNA renders a highly aggressive phenotype in vitro and results in the development of growing tumors when injected into nude mice. Nevertheless, and in spite of widespread consensus on the role of ACSL4 in mediating an aggressive phenotype in breast cancer, the early steps through which ACSL4 increases tumor growth and progression have been scarcely described and need further elucidation. For this reason, the goal of this work was to study the gene expression profile and the signaling pathways triggered by ACSL4 overexpression in the mechanism that leads to an aggressive phenotype in breast cancer.

Methods: We have performed a massive in-depth mRNA sequencing approach and a reverse-phase protein array using MCF-7 Tet-Off/ACSL4 cells as a model to identify gene expression and functional proteomic signatures specific to ACSL4 overexpression.

Results and Conclusion: The sole expression of ACSL4 displays a distinctive transcriptome and functional proteomic profile. Furthermore, gene networks most significantly upregulated in breast cancer cells overexpressing ACSL4 are associated to the regulation of embryonic and tissue development, cellular movement and DNA replication and repair. In conclusion, ACSL4 is an upstream regulator of tumorigenic pathways. Because an aggressive tumor phenotype appears in the early stages of metastatic progression, the previously unknown mediators of ACSL4 might become valuable prognostic tools or therapeutic targets in breast cancer.

Keywords: Acyl-CoA synthetase 4; Gene signature; Transcriptome; Functional proteomics; Breast cancer

\section{Introduction}

Breast cancer remains the second most important cause of death (by cancer) among women [1]. Patients who cannot be cured are those in whom breast cancer has metastasized, that is, breast cancer cells have migrated and invaded other organs such as lung and bone. As no effective therapies are currently available, aggressive breast cancer constitutes a key field for both researchers and clinicians. It has been shown that both in breast cancer cell lines and in tumor samples the expression of acyl-CoA synthetase 4 (ACSL4) is directly correlated with aggressiveness in breast cancer and inversely correlated with estrogen receptor alpha (ER $\alpha)$ levels [2-4]. ACSL4 belongs to a five-member family of enzymes that esterifies mainly arachidonic acid (AA) into acyl-CoA [2-5]. Unlike the other ACSL isoforms, ACSL4 is encoded on the $\mathrm{X}$ chromosome and its expression is highest in adrenal cortex, ovary and testis [6-10], as well as in mouse and human cerebellum and hippocampus [11]. Studies on the physiological functions of ACSL4 have revealed possible roles in polyunsaturated fatty acid metabolism in brain, in steroidogenesis, in eicosanoid metabolism related to apoptosis and embryogenesis [8-14]. ACSL4 expression has also been associated with non-physiological functions such as mental retardation disorder $[15,16]$ and cancer $[2,3,17,18]$. ACSL4 was first associated with cancer due to its abnormal expression in colon and hepatocellular carcinoma. Increased ACSL4 expression, both at mRNA and protein levels [18], in colon adenocarcinoma cells has been associated with the inhibition of apoptosis and an increase in cell proliferation when compared to adjacent normal tissue. ACSL4 has also been suggested as a predictive factor for drug resistance in breast cancer patients receiving adriamycin-containing chemotherapy [19]. We have demonstrated a positive correlation of ACSL4 expression and aggressiveness in breast cancer cell lines, with the highest expression found in metastatic lines derived from triple-negative tumor breast cancer (MDA-MB-231 and Hs578T) [3]. Functionally, we have found that ACSL4 is part of the mechanism responsible for increased breast cancer cell proliferation, invasion and migration, both in vitro and in vivo $[3,4]$. We have further demonstrated that ACSL4 can be silenced to reduce cell line aggressiveness. The role of ACSL4 in the development of growing tumors found further support when tumor growth was inhibited through the inhibition of ACSL4 expression [5]. However, even if the role of ACSL4 in mediating an aggressive phenotype in breast cancer is well accepted, its underlying mechanisms have been scarcely explored. For this reason, the goal of this work was to study the gene expression profile and the signaling pathways triggered by ACSL4 overexpression in the mechanism that leads to an aggressive phenotype in breast cancer. Thus, we have performed a massive in-depth mRNA sequencing approach and a reverse-phase protein array using ACSL4overexpressing MCF-7 cells, as a model to identify gene expression and functional proteomic signatures specific to ACSL4 overexpression.

\section{Materials and Methods}

\section{Cell culture}

The human breast cancer cell line was generously provided by Dr.

*Corresponding author: Ernesto J Podesta, Biomedical Research Institute, Inbiomed, Department of Biochemistry, School of Medicine University of Buenos Aires, CABA, C1121ABG, Argentina, Tel: 541149644027; E-mail: ernestopodesta@ yahoo.com.ar

Received October 23, 2015; Accepted November 20, 2015; Published November 23, 2015

Citation: Castillo AF, Orlando UD, Lopez P, Solano AR, Maloberti PM, et al. (2015) Gene Expression Profile and Signaling Pathways in MCF-7 Breast Cancer Cells Mediated by Acyl-CoA Synthetase 4 Overexpression. Transcriptomics 3: 120. doi:10.4172/2329-8936.1000120

Copyright: (c) 2015 Castillo AF, et al. This is an open-access article distributed under the terms of the Creative Commons Attribution License, which permits unrestricted use, distribution, and reproduction in any medium, provided the original author and source are credited. 
Vasilios Papadopoulos (Research Institute of the McGill University Health Centre, Montreal, Canada) and obtained from the Lombardi Comprehensive Cancer Center (Georgetown University Medical Center, Washington D.C., USA). The tetracycline-repressible MCF-7 cell lines, designated MCF-7 Tet-Off empty vector, and MCF-7 TetOff-induced repression of ACSL4, designated MCF-7 Tet-Off/ACSL4, were obtained previously in the laboratory [3]. The cell lines were maintained in Dulbecco's modified Eagle (DMEM) medium (GIBCO, Invitrogen Corporation, Grand Island, NY, USA) supplemented with $10 \%$ Fetal calf serum (PAA laboratories $\mathrm{GmbH}$, Pasching, Austria) plus $100 \mathrm{U} / \mathrm{ml}$ penicillin and $10 \mathrm{mg} / \mathrm{ml}$ streptomycin (GIBCO, Invitrogen Corporation,Grand Island, NY, USA). Doxycycline (Sigma Chemical Co.,St. Louis, MO, USA), a more stable tetracycline analogue, was used to regulate the expression of the Tet-Off system. Sterile and plastic material for tissue culture was from Orange Scientific (Braine-l'Alleud, Belgium). All other reagents were of the highest grade available.

\section{RNA-Seq sample preparation and sequencing}

For each cell line, total RNA was extracted by Direct-zol RNA kit (Zymo Research, Irvine, CA, USA). RNA quality was assessed by agarose gel electrophoresis (visual absence of significant $28 \mathrm{~S}$ and $18 \mathrm{~S}$ rRNA degradation) and by spectrophotometry. RNA-Seq was performed by Zymo Research facility performing PolyA enrichment of the RNA samples. HiSeq $2 \times 50$ bp paired-ends reads from RNASeq of a human normal-tumor pair samples were analyzed first using the TopHat and Cufflinks software. TopHat (v2.0.6) was utilized for alignment of short reads to GRCh37, Cufflinks (v2.0.2) for isoform assembly and quantification, and commeRbund (v2.0.0) for visualization of differential analysis. Default parameters were used. The RNA-Seq quality control was performed using Dispersion, Volcano, MA, Density, PCA, Scatter and Box plots.

\section{Quantitative reverse transcription-PCR (qRT-PCR)}

MCF-7 Tet-Off empty vector and MCF-7 Tet-Off/ACSL4 total RNA was extracted using Tri-Reagent (Molecular Research Center, Cincinnati, OH, USA) following the manufacturer's instructions. Any residual genomic DNA was removed by treating RNA with DNase I (Invitrogen, Carlsbad, CA, USA) at room temperature for $15 \mathrm{~min}$, which was subsequently inactivated by incubation with $2.5 \mathrm{mM}$ EDTA for $10 \mathrm{~min}$ at $65^{\circ} \mathrm{C}$. Two $\mu \mathrm{g}$ of total RNA were reverse transcribed using random hexamers and M-MLV Reverse Transcriptase (Promega, Madison, WI, USA) according to the manufacturer's protocol. For realtime PCR, gene specific primers were obtained from RealTimePrimers. com (Elkins Park, PA, USA). Real-time PCR was performed using Applied Biosystems 7300 Real-Time PCR System and $20 \mu \mathrm{l}$ of a solution containing $5 \mu \mathrm{l}$ of $\mathrm{cDNA}, 10 \mu \mathrm{M}$ forward and reverse primers, and 10 $\mu \mathrm{l}$ of SYBR Select Master Mix (Applied Biosystems, Carlsbad, CA, USA) for each reaction. All reactions were performed in triplicate. Amplification was initiated by a 2 -min preincubation at $50^{\circ} \mathrm{C}, 2$-min incubation at $95^{\circ} \mathrm{C}$, followed by 40 cycles at $95^{\circ} \mathrm{C}$ for $15 \mathrm{sec}, 55^{\circ} \mathrm{C}$ for $15 \mathrm{sec}$ and $72^{\circ} \mathrm{C}$ for $1 \mathrm{~min}$, terminating at $95^{\circ} \mathrm{C}$ for the last $15 \mathrm{sec}$. Gene mRNA expression levels were normalized to human 18S RNA expression, performed in parallel as endogenous control. Real-time PCR data were analyzed by calculating the $2^{-\Delta \Delta \mathrm{Ct}}$ value (comparative $\mathrm{Ct}$ method) for each experimental sample.

\section{David and Ingenuity Pathways Analysis}

To identify the statistically significant biological functions and signaling pathways affected by the genes differentially expressed in our comparisons, we used Database for Annotation, Visualization and Integrated Discovery (DAVID) [20] and Ingenuity Pathways Analysis
(IPA; Ingenuity Systems, Inc., Cambridge, MA, USA) [21]. IPA is the largest curated database and analysis system for understanding the signaling and metabolic pathways, molecular networks and biological processes that are most significantly changed in a dataset of interest. Ranking and significance of the biofunctions and the canonical pathways were tested by the $p$-value. Additionally, canonical pathways were ordered by the ratio (number of genes from the input data set that map to the pathway divided by the total number of molecules that exist in the canonical pathway). IPA also generated cellular networks where the differentially regulated genes were related according to previously known associations between genes or proteins, but independently of established canonical pathways. Top networks represent associative network functions based on a score that considers the -log ( $p$-value), which aggregates the likelihood that genes in the network are found together due to random chance.

\section{Reverse phase protein assay (RPPA)}

RPPA was performed in the RPPA Core Facility - Functional Proteomics from MD -Anderson Cancer Center, University of Texas, TX, USA. Cellular proteins were denatured by $1 \%$ SDS (with betamercaptoethanol) and diluted in five 2-fold serial dilutions in dilution buffer (lysis buffer containing 1\% SDS). Serial diluted lysates were arrayed on nitrocellulose-coated slides (Grace Biolab) by Aushon 2470 Arrayer (Aushon BioSystems) [22].

\section{Statistical Analysis}

Data analysis was performed using GraphPad InStat Software 3.01 (La Jolla, CA, USA). Statistical significance was determined by analysis of variance (ANOVA) followed by Tukey- Kramer Multiple Comparison Test and Spearman's rank correlation coefficient was calculated using Social Science Statistics free statistics software.

\section{Results and Discussion}

\section{Differential gene expression triggered by ACSL4}

As ACSL4 plays a crucial role in tumor growth, we have undertaken a systematic study to identify genes with tumorigenesis capacity and elucidate the underlying signaling mechanism. Toward understanding the capacity of ACSL4 in the regulation of tumorigenesis, we have previously reported the involvement of AA lipoxygenase and cyclooxygenase metabolites in the action of ACSL4 $[3,4]$ and, in this report, we focus on the identification of ACSL4-responsive genes using the RNA-Seq in MCF-7 Tet-Off/ACSL4 compared with an MCF-7 Tet-Off empty vector. This system is particularly valuable in enabling both the overexpression and the specific inhibition of ACSL4 through doxycycline treatment and has been previously used to develop tumors in xenograft models $[3,4]$. Results show a total of 26705366 RNA-Seq reads acquired from MCF-7 Tet-Off/ACSL4 and 22258811 reads acquired from MCF-7 Tet-Off empty vector. We next aligned the sequence reads to a human genome reference (GRCh37) using TopHat version 2.0.6, with results rendering $93.30 \%$ of the MCF-7 Tet-Off/ACSL4 reads and $92.90 \%$ of the MCF-7 Tet-Off empty vector reads as successfully mapped. The resulting read alignments (file format: BAM) were then assembled through Cufflinks version 2.0.2 for isoform assembly and quantification, and commeRbund (v2.0.0) for visualization of differential analysis (default parameters were used). The RNA-Seq quality control was performed using Dispersion, Volcano, MA, Density, PCA, Scatter and Box plots. Gene expression levels were determined by measuring the sum of fragments per kilobase of exon model per million of reads mapped (FPKM), analyzed in each exon. To acquire more accurate results, data were filtered out whenever 
estimated FPKM values in both MCF-7 Tet-Off/ACSL4 and MCF-7 Tet-Off empty vector samples were less than 1.0 (cf. an FPKM value of 0.05 is commonly set as the lowest boundary of expression level). Only loci having a $\log _{2}$ (fold change) $>2$ between MCF-7 Tet-Off/ACSL4 and MCF-7 Tet-Off empty vector were considered. Ultimately, we observed that, from 32247 successfully sequenced loci, 3944 were significantly and differentially expressed in MCF-7 Tet-Off/ACSL4 samples. Among them, 2501 were upregulated and 1443 were downregulated. ACSL4 gene was one of the genes taken as a control of its overexpression and, as expected, it was one of the genes showing major differences between MCF-7 Tet-Off/ACSL4 and MCF-7 Tet-Off empty vector. Table 1 shows the top genes which exhibit differential changes when ACSL4 is overexpressed. To determine the characteristic chromosomal location of genes controlled by ACSL4 expression, we used the CROC program [23] to examine the expression landscape by plotting the number of differentially expressed genes along the whole chromosomes. Results revealed that chromosome distribution patterns varied greatly with respect to gene density and, in particular, chromosome 1 showed the highest gene density among genes mapped (Figure S1). A total of 52 clusters were found -chromosome 1 showed the highest number of clusters (8)-, while the number of genes in clusters was 181 .

\section{Enriched functional categories of gene networks relating to the transcripts regulated by ACSL4 overexpression}

To gain insights into biological cell properties, IPA was used to rank enriched functional categories of gene networks relating to the transcripts regulated in ACSL4-responsive gene sets acquired from the RNA-Seq data. The highest-scoring associated diseases and disorders are shown in Table 2, while cancer was the disease showing the lowest $p$-value among diseases and disorders. As a result, we verified 390 top biofunctions concerned with the ACSL4-induced transcriptome alteration in MCF-7 Tet-Off/ACSL4 cells. The most significantly tumorigenesisrelated biofunctions (only $p$-values under 0.01) are shown in Table 3. In agreement with our previous results regarding ACSL4 effect on cell proliferation, invasion and migration [3,4], the top three biofunctions which were IPA-predicted to be increased in RNA-Sec data were cell movement migration and proliferation. Table S1 shows a detailed list of molecules altered in these biofunctions. Table 4 shows the top ten most significantly upregulated functions related to gene networks in the RNA-Seq -along with a list of the corresponding genes in each function network-, while Figure S2 shows the network corresponding to the top ten upregulated functions. DNA replication,

\begin{tabular}{|c|c|c|c|c|}
\hline \multicolumn{5}{|l|}{ GENES UPREGULATED } \\
\hline Name & Gene Symbol & Location & Type(s) & $\log _{2}$ fold change \\
\hline NADPH oxidase 3 & NOX3 & cytoplasm & enzyme & 13.21 \\
\hline De-etiolated homolog 1 (Arabidopsis) & DET1 & nucleus & other & 10.97 \\
\hline Patched 2 & $\mathrm{PTCH} 2$ & plasma membrane & transmembrane receptor & 10.9 \\
\hline Wingless-type MMTV integration site family, member 6 & WNT6 & extracellular space & other & 6.74 \\
\hline Zinc finger, matrin-type 4 & ZMAT4 & nucleus & other & 5.02 \\
\hline Retinoic acid induced 2 & $R A / 2$ & unknown & other & 4.75 \\
\hline Dual specificity phosphatase 18 & DUSP18 & cytoplasm & phosphatase & 4.69 \\
\hline Transcription factor B1, mitochondrial & TFB1M & cytoplasm & transcription regulator & 4.58 \\
\hline MAP/microtubule affinity-regulating kinase 1 & MARK1 & cytoplasm & kinase & 4.30 \\
\hline Interleukin 20 & IL20 & extracellular space & cytokine & 4.29 \\
\hline Fatty acyl CoA reductase 2 & FAR2 & cytoplasm & enzyme & 4.16 \\
\hline Ets homologous factor & $E H F$ & nucleus & transcription regulator & 4.09 \\
\hline SH3-domain GRB2-like 3 & SH3GL3 & cytoplasm & other & 4.06 \\
\hline 2'-5'-oligoadenylate synthetase $1,40 / 46 \mathrm{kDa}$ & OAS1 & cytoplasm & enzyme & 4.05 \\
\hline Synaptotagmin XIII & SYT13 & plasma membrane & transporter & 3.85 \\
\hline Aldehyde oxidase 1 & AOX1 & cytoplasm & enzyme & 3.78 \\
\hline G protein, alpha inhibiting activity & GNAI1 & plasma membrane & enzyme & 3.78 \\
\hline FXYD domain containing ion transport regulator 5 & FXYD5 & plasma membrane & ion channel & 3.75 \\
\hline Cytochrome c oxidase subunit VIIb2 & COX7B2 & unknown & unknown & 3.73 \\
\hline Wingless-type MMTV integration site family, member $10 \mathrm{~A}$ & WNT10A & extracellular space & other & 3.60 \\
\hline Interferon, alpha-inducible protein 6 & IFI6 & cytoplasm & other & 3.35 \\
\hline Sp6 transcription factor & SP6 & nucleus & transcription regulator & 3.35 \\
\hline Acyl-CoA oxidase 2 , branched chain & ACOX2 & cytoplasm & enzyme & 3.31 \\
\hline Transforming growth factor, beta 2 & TGFB2 & extracellular space & growth factor & 3.22 \\
\hline Interleukin 24 & IL24 & extracellular space & cytokine & 3.15 \\
\hline GABA(A) receptor-associated protein like 1 & GABARAPL1 & cytoplasm & other & 2.54 \\
\hline FBJ murine osteosarcoma viral oncogene homolog & FOS & nucleus & transcription regulator & 2.41 \\
\hline Laminin, beta 1 & LAMB1 & extracellular space & other & 2.37 \\
\hline Nuclear receptor coactivator 4 & NCOA4 & nucleus & transcription regulator & 2.09 \\
\hline Phospholipase D1, phosphatidylcholine-specific & PLD1 & cytoplasm & enzyme & 2.09 \\
\hline v-Erb-b2 & $E R B B 2$ & plasma membrane & kinase & 2.05 \\
\hline Fibroblast growth factor 11 & FGF11 & extracellular space & other & 2.04 \\
\hline Ret proto-oncogene & $R E T$ & plasma membrane & kinase & 2.04 \\
\hline Fibroblast growth factor receptor 1 & FGFR1 & plasma membrane & kinase & 2.04 \\
\hline Integrin, alpha 2 (CD49B, alpha 2 subunit of VLA-2 receptor) & ITGA2 & plasma membrane & transmembrane receptor & 2.02 \\
\hline Eukaryotic translation initiation factor 2-alpha kinase 2 & EIF2AK2 & cytoplasm & kinase & 1.94 \\
\hline Unc-51 like autophagy activating kinase 1 & ULK1 & cytoplasm & kinase & 1.83 \\
\hline Vascular endothelial growth factor A & VEGFA & extracellular space & group & 1.75 \\
\hline
\end{tabular}


Citation: Castillo AF, Orlando UD, Lopez P, Solano AR, Maloberti PM, et al. (2015) Gene Expression Profile and Signaling Pathways in MCF-7 Breast Cancer Cells Mediated by Acyl-CoA Synthetase 4 Overexpression. Transcriptomics 3: 120. doi:10.4172/2329-8936.1000120

Page 4 of 9

\section{GENES DOWNREGULATED}

\begin{tabular}{|l|c|c|c|}
\hline Name & Gene Symbol & Location & Type(s) \\
\hline Protein tyrosine phosphatase, non-receptor type 22 & PTPN22 & cytoplasm & phosphatase \\
\hline ADAM metallopeptidase with thrombospondin type 1 motif, 9 & ADAMTS9 & extracellular space & peptidase \\
\hline Prickle homolog 2 & PRICKLE2 & nucleus & other \\
\hline Neurotrophic tyrosine kinase, receptor, type 3 & NTRK3 & plasma membrane & kinase \\
\hline Contactin associated protein-like 3B & CNTNAP3B & unknown & other \\
\hline WNT inhibitory factor 1 & WIF1 & extracellular space & other \\
\hline Keratin, Type I cytoskeletal 20 & CK20 (KRT20) & cytoplasm & other \\
\hline Deiodinase, iodothyronine, type II & DIO2 & cytoplasm & enzyme \\
\hline Zinc finger protein 217 & ZNF217 & nucleus & transcription regulator \\
\hline Ca ${ }^{++}$-dependent secretion activator & CADPS & plasma membrane & -4.29 \\
\hline
\end{tabular}

Table 1: Identification of significantly upregulated and downregulated genes by ACSL4 overexpression using RNA-Seq

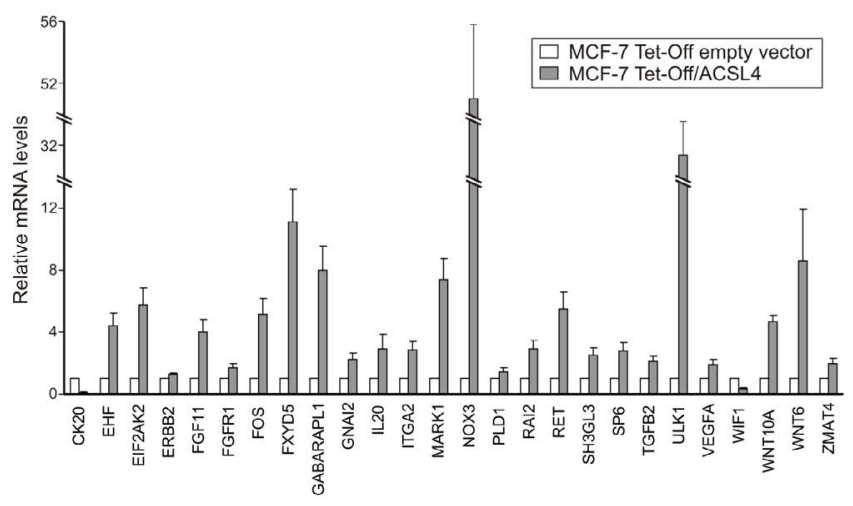

Figure 1: Real-time RT-PCR analysis of the top genes exhibiting differential changes in RNA-Seq when ACSL4 is overexpressed. Total RNA was isolated from MCF-7 Tet-Off empty vector and MCF-7 Tet-Off/ACSL4 cells, reverse transcribed and subjected to real-time PCR using specific primers. Each transcript expression level was normalized to human 18S RNA expression, performed in parallel as endogenous control. Real-time PCR data were analyzed by calculating the $2^{-\Delta \Delta C t}$ value (comparative $\mathrm{Ct}$ method) for each experimental sample. Relative mRNA expression levels are shown. Data are presented as mean \pm standard deviation (SD)

\begin{tabular}{|l|c|c|}
\hline Name of Diseases and Disorders & p-value & \# molecules \\
\hline Cancer & $5.74 \mathrm{E}-07-0.0191$ & 530 \\
\hline Infectious Disease & $4.56 \mathrm{E}-05-0.0174$ & 136 \\
\hline Reproductive System Disease & $7.35 \mathrm{E}-05-1.87 \mathrm{E}-02$ & 163 \\
\hline $\begin{array}{l}\text { Dermatological Diseases and } \\
\text { Conditions }\end{array}$ & $8.42 \mathrm{E}-05-0.0141$ & 74 \\
\hline Endocrine System Disorders & $1.09 \mathrm{E}-04-0.0197$ & 78 \\
\hline
\end{tabular}

Table 2: Top associated diseases and disorders analyzed by IPA. Top significantly diseases and disorders concerned with the ACSL4-induced transcriptome alteration in MCF-7 Tet-Off/ACSL4 cells.

\begin{tabular}{|l|c|c|c|c|c|}
\hline Category & $\begin{array}{c}\text { Diseases or } \\
\text { Functions } \\
\text { Annotation }\end{array}$ & p-value & $\begin{array}{c}\text { Predicted } \\
\text { Activation } \\
\text { State }\end{array}$ & $\begin{array}{c}\text { Activation } \\
\text { z-score }\end{array}$ & $\begin{array}{c}\# \\
\text { Molecules }\end{array}$ \\
\hline $\begin{array}{l}\text { Cellular } \\
\text { Movement }\end{array}$ & cell movement & $3.97 \mathrm{E}-07$ & Increased & 4.685 & 182 \\
\hline $\begin{array}{l}\text { Cellular } \\
\text { Movement }\end{array}$ & $\begin{array}{c}\text { migration of } \\
\text { cells }\end{array}$ & $4.65 \mathrm{E}-07$ & Increased & 4.677 & 166 \\
\hline $\begin{array}{l}\text { Cellular Growth } \\
\text { and Proliferation }\end{array}$ & $\begin{array}{c}\text { proliferation of } \\
\text { cells }\end{array}$ & $2.04 \mathrm{E}-06$ & Increased & 2.390 & 295 \\
\hline $\begin{array}{l}\text { Cellular Assembly } \\
\text { and Organization }\end{array}$ & $\begin{array}{c}\text { formation } \\
\text { of cellular } \\
\text { protrusions }\end{array}$ & $7.15 \mathrm{E}-05$ & Increased & 3.830 & 73 \\
\hline $\begin{array}{l}\text { Cellular Assembly } \\
\text { and Organization }\end{array}$ & $\begin{array}{c}\text { microtubule } \\
\text { dynamics }\end{array}$ & $1.48 \mathrm{E}-04$ & Increased & 4.169 & 94 \\
\hline $\begin{array}{l}\text { Cellular Assembly } \\
\text { and Organization } \\
\text { of }\end{array}$ & $\begin{array}{c}1.89 \mathrm{E}-04 \\
\text { cytoskeleton }\end{array}$ & Increased & 3.662 & 107 \\
\hline
\end{tabular}

\begin{tabular}{|c|c|c|c|c|c|}
\hline $\begin{array}{l}\text { Gene } \\
\text { Expression }\end{array}$ & transactivation & 3.17E-04 & Increased & 3.318 & 59 \\
\hline $\begin{array}{l}\text { Cellular Assembly } \\
\text { and Organization }\end{array}$ & $\begin{array}{l}\text { organization } \\
\text { of cytoplasm }\end{array}$ & 3.73E-04 & Increased & 3.714 & 113 \\
\hline $\begin{array}{l}\text { Carbohydrate } \\
\text { Metabolism }\end{array}$ & $\begin{array}{c}\text { sulfation of } \\
\text { polysaccharide }\end{array}$ & 4.39E-04 & Increased & 2.132 & 5 \\
\hline $\begin{array}{l}\text { Gene } \\
\text { Expression }\end{array}$ & $\begin{array}{c}\text { transactivation } \\
\text { of RNA }\end{array}$ & $9.23 \mathrm{E}-04$ & Increased & 3.718 & 54 \\
\hline Cancer & $\begin{array}{c}\text { proliferation of } \\
\text { cancer cells }\end{array}$ & $1.05 E-03$ & Increased & 2.009 & 37 \\
\hline $\begin{array}{l}\text { Cellular Assembly } \\
\text { and Organization }\end{array}$ & $\begin{array}{l}\text { formation } \\
\text { of plasma } \\
\text { membrane } \\
\text { projections }\end{array}$ & $1.20 \mathrm{E}-03$ & Increased & 2.128 & 49 \\
\hline $\begin{array}{l}\text { Cellular Growth } \\
\text { and Proliferation }\end{array}$ & $\begin{array}{l}\text { proliferation } \\
\text { of connective } \\
\text { tissue cells }\end{array}$ & 1.45E-03 & Increased & 2.628 & 54 \\
\hline $\begin{array}{l}\text { Cellular } \\
\text { Development }\end{array}$ & $\begin{array}{l}\text { branching of } \\
\text { cells }\end{array}$ & 1.60E-03 & Increased & 3.043 & 17 \\
\hline $\begin{array}{l}\text { Cellular } \\
\text { Movement }\end{array}$ & $\begin{array}{c}\text { cell movement } \\
\text { of tumor cell } \\
\text { lines }\end{array}$ & 2.20E-03 & Increased & 2.034 & 67 \\
\hline $\begin{array}{l}\text { Cellular } \\
\text { Movement }\end{array}$ & $\begin{array}{l}\text { migration of } \\
\text { tumor cell } \\
\text { lines }\end{array}$ & 2.26E-03 & Increased & 2.139 & 55 \\
\hline $\begin{array}{l}\text { Cellular } \\
\text { Movement }\end{array}$ & $\begin{array}{l}\text { cell movement } \\
\text { of tumor cells }\end{array}$ & $2.41 \mathrm{E}-03$ & Increased & 2.530 & 19 \\
\hline Cell Morphology & $\begin{array}{l}\text { shape change } \\
\text { of tumor cell } \\
\text { lines }\end{array}$ & 5.81E-03 & Increased & 2.180 & 16 \\
\hline $\begin{array}{l}\text { Cellular } \\
\text { Development }\end{array}$ & $\begin{array}{l}\text { differentiation } \\
\text { of stem cells }\end{array}$ & 8.78E-03 & Increased & 2.540 & 21 \\
\hline Cancer & $\begin{array}{l}\text { prostate } \\
\text { cancer and } \\
\text { tumors }\end{array}$ & 1.17E-02 & Increased & 2.200 & 54 \\
\hline $\begin{array}{l}\text { Cellular Assembly } \\
\text { and Organization }\end{array}$ & $\begin{array}{l}\text { growth of } \\
\text { plasma } \\
\text { membrane } \\
\text { projections }\end{array}$ & 1.18E-02 & Increased & 2.866 & 40 \\
\hline $\begin{array}{l}\text { Cellular } \\
\text { Movement }\end{array}$ & $\begin{array}{l}\text { migration of } \\
\text { tumor cells }\end{array}$ & 1.26E-02 & Increased & 2.089 & 20 \\
\hline $\begin{array}{l}\text { Cell } \\
\text { Morphology }\end{array}$ & $\begin{array}{c}\text { shape change } \\
\text { of neurons }\end{array}$ & 1.26E-02 & Increased & 2.205 & 6 \\
\hline
\end{tabular}

Table 3: Top associated biofunctions by IPA. Top significantly tumorigenesisrelated biofunctions concerned with the ACSL4-induced transcriptome alteration in MCF-7 Tet-Off/ACSL4 cells. Only p-values under 0.01 calculated by right-tailed Fisher's Exact test were considered significant. IPA uses the activation z-score algorithm to make predictions. The $z$-score algorithm is designed to reduce the chance that random data will generate significant predictions. 
Citation: Castillo AF, Orlando UD, Lopez P, Solano AR, Maloberti PM, et al. (2015) Gene Expression Profile and Signaling Pathways in MCF-7 Breast Cancer Cells Mediated by Acyl-CoA Synthetase 4 Overexpression. Transcriptomics 3: 120. doi:10.4172/2329-8936.1000120

Page 5 of 9

\begin{tabular}{|c|c|c|c|}
\hline Network & Score & Focus Molecules & $\begin{array}{l}\text { Top Diseases and } \\
\text { Functions }\end{array}$ \\
\hline 1 & 44 & 33 & $\begin{array}{c}\text { DNA Replication, } \\
\text { Recombination, and } \\
\text { Repair, Gene Expression, } \\
\text { Cancer }\end{array}$ \\
\hline 2 & 43 & 32 & $\begin{array}{l}\text { Carbohydrate Metabolism, } \\
\text { Small Molecule } \\
\text { Biochemistry, Post- } \\
\text { Translational Modification }\end{array}$ \\
\hline 3 & 35 & 28 & $\begin{array}{l}\text { Molecular Transport, } \\
\text { Hereditary Disorder, } \\
\text { Neurological Disease }\end{array}$ \\
\hline 4 & 31 & 26 & $\begin{array}{l}\text { Cellular Development, } \\
\text { Embryonic Development, } \\
\text { Developmental Disorder }\end{array}$ \\
\hline 5 & 31 & 26 & $\begin{array}{l}\text { Cardiovascular Disease, } \\
\text { Cancer, Dermatological } \\
\text { Diseases and Conditions }\end{array}$ \\
\hline 6 & 31 & 26 & $\begin{array}{c}\text { Carbohydrate Metabolism, } \\
\text { Tissue Morphology, } \\
\text { Ophthalmic Disease }\end{array}$ \\
\hline 7 & 29 & 25 & $\begin{array}{c}\text { Cell Morphology, Hair } \\
\text { and Skin Development } \\
\text { and Function, Organ } \\
\text { Morphology }\end{array}$ \\
\hline 8 & 29 & 25 & $\begin{array}{l}\text { Cell Morphology, Cellular } \\
\text { Compromise, Lipid } \\
\text { Metabolism }\end{array}$ \\
\hline 9 & 29 & 25 & $\begin{array}{c}\text { Cancer, Dermatological } \\
\text { Diseases and Conditions, } \\
\text { Hematological Disease }\end{array}$ \\
\hline 10 & 29 & 25 & $\begin{array}{l}\text { Endocrine System } \\
\text { Development and } \\
\text { Function, Small } \\
\text { Molecule Biochemistry, } \\
\text { Developmental Disorder }\end{array}$ \\
\hline
\end{tabular}

\section{Molecules in Network}

CALCOCO1, CBX2, CBX5, CBX8, CHRNE, DIAPH2, ELF5, HIST1H3A (includes others), HIST1H4A (includes others), HIST2H2AA3/HIST2H2AA4, HIST2H2AC, HIST2H2BE (includes others), HIST2H3C (includes others), HIST3H2A, HOXD8, IL20, IL17R, IL17RC, KLF11, MSL3, MSMB, MT1G, NEK3, PARP10, RCC1, S100A7, SCML1, SHISA2, TEAD4, TFAP2C, TRANK1, TTC1, Vegf, WDR61, ZNF324B

A4GALT, ATL1, B4GALT1, B4GALT5, B4GALT6, B4GALT7, CDC42EP5, CMTM8, CYP4Z1, DSC2, EMCN, ERK1/2, ETV4, FAIM3, Galactosyltransferase beta 1, 4, GLIPR2, HS6ST2, KLF13, LINGO1, LRRN1, MMD, MUC5B, NDST1, NMU, OLFM1, PKP2, RAPGEF2, RTKN, RTN4R, RTN4RL2, SHC4, ST6GAL1, sulfotransferase, TP53TG1, ZNF217

ANO3, AP-3, AP3B2, AP3D1, ATP6V0A4, ATP6V0B, ATP6V1C2, CBR3, DOK3, EDARADD, EHF, ENO3, FBXO41, $\mathrm{H}$ +-exporting ATPase, $H+$ +transporting two sector ATPase, KCND3, MIB2, MTORC1, NFIX, NFkB (complex), PDCD11, PGM1, PNKD, PRMT2, PRPH, RFTN1, S100, S100A1, S100P, SGCB, SGCG, TFEB, TMOD2, Vacuolar H+ ATPase, ZNF385A

ADAMTS9, ADCY, ADCY6, AGPAT9, Angiotensin II receptor type 1, BIK, C8orf4, CAPN8, DGAT2, EYA2, Fascin, FATE1, FSCN2, GABRB3, GGT5, GNAI1, HOXA5, INSIG2, IRS, Nr1h, NUCB1, p70 S6k, PADI2, PDE4D, PDE4DIP, Pkc(s), PODXL, PSCA, RGS6, SIX2, SLC1A1, SOCS, SP110, TPM2, TSH

ABCC8, ABLIM1, ABLIM2, CCNG2, CRAT, DEAF1, DLX4, FOXO4, GATA6, GPX2, GUCY1A3, Hedgehog, Histone h4, ID3, KLF2, LMO2, Notch, NOTCH2, PI3K (family), PLEKHF1, PTCH1, PTCH2, QPCT, Ras, RCN1, Secretase gamma, SLC26A2, SMAD6, SMOOTH MUSCLE ACTIN, TAGLN, TCF, TNNT1, TOB2, ZC3H15

ACAA2, Alpha catenin, BMP7, BRSK1, BSG, CBR4, CDH8, CHST11, CLDN23, CNKSR3, collagen, Collagen(s), CTGF, elastase, ERBB2, estrogen receptor, FAM134B, GJB3, HSD17B, HSD17B7, HSD17B8, HSD17B14, Integrin, KIFC3, MAP2K1/2, Mmp, MMP23B, PLEK2, PRR15L, RNF149, SOWAHC, SOX4, SYNPO, TSPAN4, ZNF703

ACHE, Akt, ANTXR1, ARHGAP24, ASAH2, CHCHD2, chymotrypsin, COL18A1, COL6A2, Collagen type IV, Collagen type VI, CSF2RA, EPHB4, gelatinase, GPIIB-IIIA, GSTZ1, ITGA2, ITGB4, LAMB1, Laminin, Laminin1, MEX3B, MGLL, mir-29, MSR1, PID1, PPT1, PTTG1IP, RAP1GAP, SCARA3, SCAVENGER receptor CLASS A, STARD13, TACSTD2, TNFRSF21, Vla-4

Alpha Actinin, Alpha tubulin, Ant, ARL2BP, ASCL2, ASIC3, Beta Tubulin, calpain, CLINT1, DCDC2, DHRS2, DMTN DPYSL 2, ESPN, F Actin, FMNL1, Focal adhesion kinase, GABARAPL1, MARCKS, Mucin, PACSIN1, SHROOM3, SLC25A4, SLC25A6, SNX33, Spectrin, STOM, Talin, TBC1D2B, TOMM2OL, TPT1, TRDMT1, TSPO, VDAC1, WAS

60S ribosomal subunit, ANKRD13B, ATR, CCDC22, CCDC53, CCDC93, CKB, COL11A2, Collagen type II, CTSL, DNAJC27, Dynamin, E2F8, ENaC, ERRFI1, FAM21A/FAM21C, HSP, Hsp27, Hsp70, HSPA8, let-7, mGluR, NXT2, OPTN, p85 (pik3r), RPL39, RPLP1, RRM2, SH3GL3, TM4SF1, TNRC6C, TRPC1, Ubiquitin, UCHL1, ZNF219

ACPP, ACSS1, ADRB, AGBL2, ATP9A, BOK, C8G, CA4, Cg, CHST8, Creb, DIO2, EPHB6, FAM198B, FAM214A, FSH, Igm, KHDRBS3, Lh, LIMCH1, MAMLD1, Mek, OGFR, ONECUT1, PLC, PTPN21, PTTG1, RAB33B, Raf, Rap1, RETSAT, SGSM2, SLCO4A1, TP53I11, YPEL3

Table 4: Gene networks of ACSL4-overexpressing cells. RNA-Seq data were analyzed for significantly regulated functions using IPA. The genes associated with each function network shown in the last column are significantly regulated in the ACSL4-overexpressing cells. Score: negative exponent of $p$-value calculated by a right-tailed Fisher's Exact test, which calculates the likelihood that network eligible molecules are found together by random chance alone.

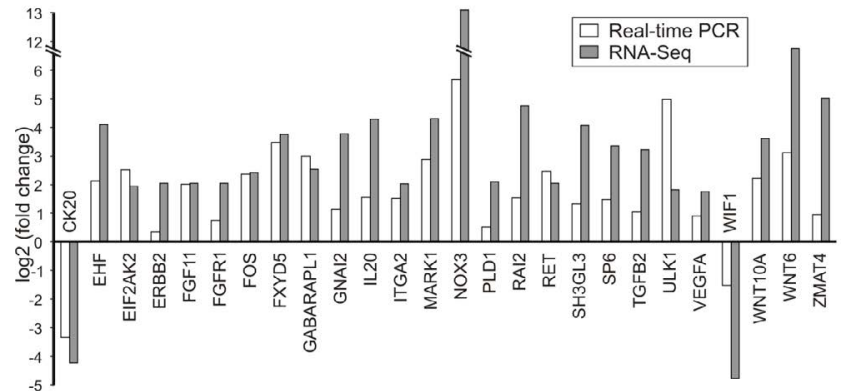

Figure 2: Validation of RNA-Seq data. Correlation between RNA-Seq and real-time PCR data of differential gene expression from MCF-7 Tet-Off/ ACSL4 to MCF-7 Tet-Off empty vector cells. Data are presented as $\log _{2}$ ratios. Spearman's rank correlation coefficient was 0.55525 and the two-tailed value of $p$ was 0.00001 . By normal standards, the positive correlation between the two variables would be considered statistically significant.

recombination, repair, gene expression and cancer showed the highest score. In particular, the finding that cellular development and embryogenesis are within the top ten biofunctions is interestingly in agreement with recent work showing the crucial role of ACSL4 pathways in embryo development in zebrafish [12] and Drosophila [14,24].

\section{RNA-Seq data confirmed by analysis of gene expression changes by real-time RT-PCR}

We further validated the gene expression changes found in RNASeq data and IPA by real-time RT-PCR in independent biologic repeats of samples from MCF-7 Tet-Off/ACSL4 and MCF-7 Tet-Off empty vector under the same conditions used for RNA-Seq analysis (relative mRNA expression levels are shown in (Figure 1). A comparison of fold changes between RNA-Seq and real-time RT-PCR for each gene is shown in Figure 2, which verifies that the real-time RT-PCR expression profiles were mostly in agreement with RNA-Seq data. Although there were small differences in the fold change values between the two methods of measurement, results were generally highly related (Spearman's rank correlation coefficient was 0.55525 and the twotailed value of $p$ was 0.00001 ) strongly supporting the reliability of our RNA-Seq analysis. We next focused our attention on categories that were relevant to this study, subgrouped these genes by function and measured an example of each of them (i.e. cytokines, transcription factors, growth factors, integrin family and cytoskeleton, Wnt signaling family, oncogenes, growth factor receptors and energy metabolism). Most of these genes have central roles in the biology of cancer cells regarding proliferation, migration and invasion. ACSL4 increased the 
expression levels of interleukin 20 IL20, Ets homologous factor (EHT), SP6 transcription factor (Krueppel-like factor 14 or SP6), transforming growth factor beta 2 (TGF $\beta 2$ ), V-erb avian erythroblastic leukemia viral oncogene homologue 2 (ERBB2), vascular endothelial growth factor A (VEFGA), integrin alpha 2 (ITGA2), MAP/Microtubule affinityregulating kinase 1 (MARK1), FXYD domain containing ion transport regulator 5 (FXYD5), ret proto-oncogen (RET), murine oesteosarcoma viral oncogene homolog (FOS), fibroblast growth factor receptor 1 (FGFR1) and Wingless-Type MMTV Integration Site Family Member 6 (WNT6) and WNT10A. One of the genes showing a marked decrease after ACSL4 expression was the WNT inhibitory factor 1 (WIF1). IL20 has been demonstrated to be upregulated in muscle-invasive bladder cancer patients, while EHT and SP6 are involved in differentiation and carcinogenesis. The SP6 has also been proposed to contribute to the malignant phenotype of breast tumors. TGF $\beta 2, E R b B 2, V E F G A$, ITGA2, MARK1, FXYD5, RET and FOS are involved in tumor progression as well. Other genes measured included the Unc-51-like autophagy-activating kinase 1 (ULK1) and the retinoic acid induced 2 (RAI2). In short, most of the genes confirmed to be upregulated here have well established roles in tumorigenesis. In addition, Table 5 shows the top small nuclear RNA and microRNA (miR) regulated by ACSL4. MicroRNAs play an important role in virtually all biological pathways and they may hence influence numerous cancer-relevant processes. ACSL4 upregulates $m i R-29 a$, whose overexpression has been described to increase tube formation and migration in endothelial cultures. Mechanistically, $m i R-29 a$ directly targets the phosphatase and tensin homolog (PTEN) in endothelial cells, leading to the activation of the AKT pathway [25]. miR let-7, an ACSL4-downregulated miR, represses cell proliferation pathways in human cells and has been described as a master regulator of cell proliferation pathways [26]. Overall, the RNA-Seq and IPA have identified genes that could potentially play important roles in the regulation of invasion and migration of breast tumor cells in vivo. We further studied enriched canonical pathways and analyzed them through IPA on the basis of RNA-Seq data. Eukaryotic translation initiation factor 2 (EIF2), protein ubiquitination, ribosomal protein $\mathrm{S} 6$ kinase $70 \mathrm{kDa}$ polypeptide 1 (p70S6K), mechanistic target of rapamycin (mTOR) and the signaling of molecular mechanisms of cancer are among the top canonical pathways triggered by ACSL 4 with the lowest $p$-values.

\section{Signal transduction pathways triggered by ACSL4 overexpression}

In order to study the signaling pathway triggered by ACSL4 on the basis of RNA-Seq bioinformatic studies, we next defined a functional protein signature of the ACSL4 pathway by using RPPA, a highthroughput antibody-based technique developed for functional

\begin{tabular}{|l|c|c|c|}
\hline Small nuclear RNA (some examples) & Gene Symbol & Location & Change \\
\hline RNA, U12 small nuclear & RNU12 & Nucleus & Upregulated \\
\hline RNA, U4 small nuclear 1 & RNU4-1 & Nucleus & Upregulated \\
\hline $\begin{array}{l}\text { RNA, U4atac small nuclear } \\
\text { (U12-dependent splicing) }\end{array}$ & RNU4ATAC & Nucleus & Upregulated \\
\hline RNA, U5A small nuclear 1 & RNU5A-1 & unknown & Upregulated \\
\hline RNA, U5D small nuclear 1 & $R N U 5 D-1$ & unknown & Upregulated \\
\hline RNA, U5E small nuclear 1 & $R N U 5 E-1$ & unknown & Upregulated \\
\hline small nucleolar RNA, H/ACA box 8 & SNORA4 & unknown & Downregulated \\
\hline Micro RNA (some examples) & Gene Symbol & Location & Change \\
\hline microRNA 29a & miR-29 & Cytoplasm & Upregulated \\
\hline microRNA 1290 & miR-1290 & Cytoplasm & Upregulated \\
\hline microRNA 25 & miR-25 & Cytoplasm & Downregulated \\
\hline microRNA let-7a-1 & let-7 & Cytoplasm & Downregulated \\
\hline microRNA let-7d & let-7 & Cytoplasm & Downregulated \\
\hline
\end{tabular}

Table 5: Top small nuclear RNA and microRNA regulated by ACSL4.

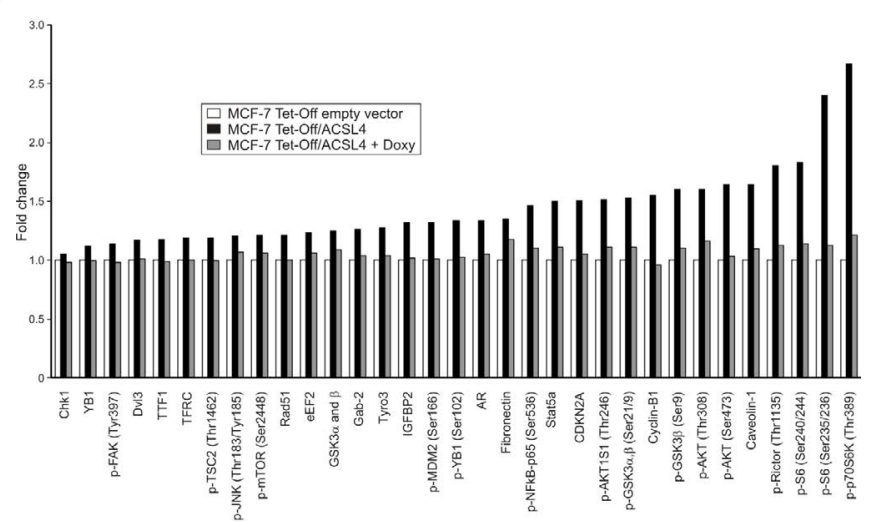

Figure 3: Identification of significantly upregulated protein expression or phosphorylation in ACSL4-overexpressing cells using RPPA. Proteins were extracted from MCF-7 Tet-Off empty vector, MCF-7 Tet-Off/ACSL4 cells and doxycycline treated-MCF-7 Tet-Off/ACSL4 (Doxy, $1 \mathrm{ug} / \mathrm{ml}, 48 \mathrm{~h}$ ) cells, and were subjected to RPPA analysis. Data are presented as fold changes (only results with $p$-values under 0.05 are shown).

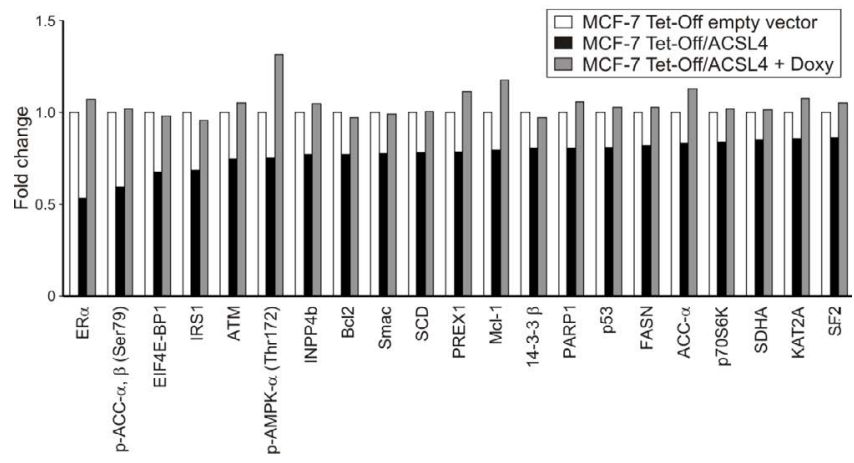

Figure 4: Identification of significantly downregulated protein expression or phosphorylation in ACSL4-overexpressing cells using RPPA. Proteins were extracted from MCF-7 Tet-Off empty vector, MCF-7 Tet-Off/ACSL4 cells and doxycycline treated-MCF-7 Tet-Off/ACSL4 (Doxy, $1 \mathrm{ug} / \mathrm{ml}, 48 \mathrm{~h}$ ) cells, and were subjected to RPPA analysis. Data are presented as fold changes (only results with $p$-values under 0.05 are shown).

proteomic studies to measure phosphorylation states, as well as total levels of key signaling pathway intermediaries. This RPPA used 217 different antibodies directed to signaling proteins or directed to specific phosphorylated sites known to regulate protein signaling activity [22]. The analysis was performed on lysates derived from MCF-7 Tet-Off/ ACSL4, MCF-7 Tet-Off empty vector and doxycycline-treated MCF-7 Tet-Off/ACSL4 cells, the latter used to specifically override ACSL4 expression. The pattern of protein expression and/or phosphorylation was remarkably different between MCF-7 Tet-Off/ACSL4 and MCF-7 Tet-Off empty vector. Lysates from doxycycline-treated MCF-7 Tet-Off/ ACSL4 cells showed a pattern similar to that of MCF-7 Tet-Off empty vector, further supporting the role of ACSL4 in the effects observed. Figures 3 and 4 show the proteins that exhibited a significant increase or decrease, respectively, in expression or phosphorylation status. ACSL4 overexpression in MCF-7 breast cancer cells changed the pattern of expression or the pattern of phospho-dephosphorylation of about fifty proteins. These effects were reversed by doxycycline treatment, which confirms the specificity of the functional proteomic signature of ACSL4. We next performed a functional annotation analysis using the bioinformatic program DAVID on the basis of RPPA data Figure 5 shows the DAVID scheme of pathways in cancer. ACSL4 overexpression stimulated the dephosphorylation of two proteins and the phosphorylation of thirteen proteins, among which it markedly 


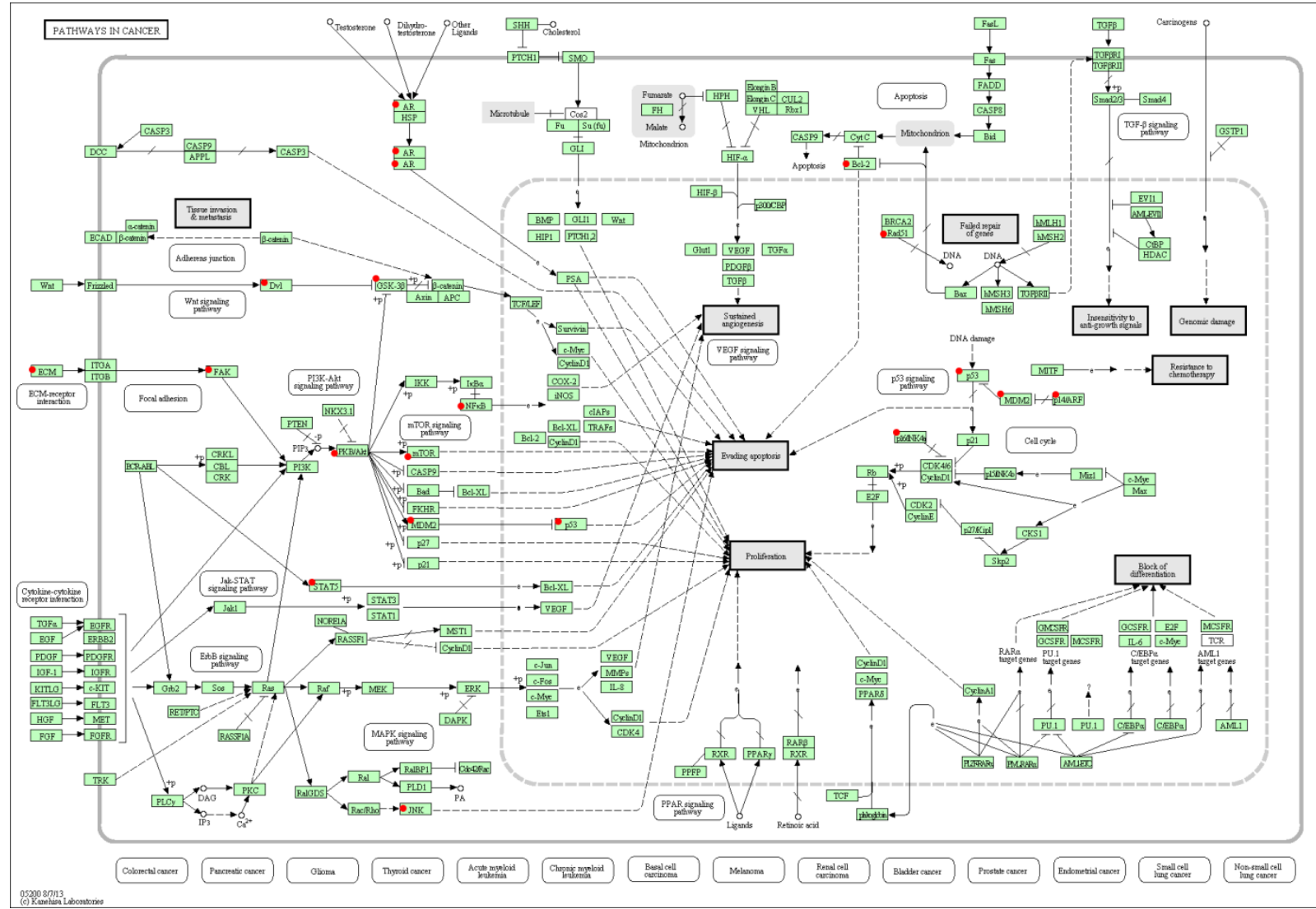

Figure 5: ACSL4 and pathways in cancer. Red marks highlight ACSL4-regulated genes in RPPA analysis. The pathway scheme was obtained from KEGG_PATHWAY database. Analysis was performed by DAVID bioinformatic tool.

stimulated the phosphorylation the mTOR pathway as previously described [22]. In accordance with the results mentioned above, ACSL4 overexpression also stimulates the expression of caveolin. Caveolin-1 is a ubiquitously expressed scaffolding protein which is enriched in caveolae -i.e. subtypes of lipid rafts- and which is involved in several cellular functions such as endocytosis, vesicular transport and signal transduction. Studies also revealed that caveolin-1 is an essential regulator of the invadopodia-mediated degradation of extracellular matrix, which indicates that caveolin-1 plays an essential role in cancer cell invasion [27]. Indeed, at least in breast cancer cell lines, caveolin-1 expression is predominantly observed in invasive cell lines and well correlated with invadopodia activity. These results correlate with those obtained in RNA-Seq, where cell movement showed the highest score (Table 3). Glycogen synthase kinase-3 alpha and beta (GSK3 $a$ and GSK3 $\beta$ ), critical negative regulators of diverse signaling pathways, are two additional phosphoproteins whose levels exhibit an important increase in response to ACSL4 overexpression, and whose phosphorylation on Ser21 and Ser9, respectively, inhibits GSK3 activity. GSK3 has also been implicated in the negative regulation of FAK (focal adhesion kinase) activity [28]. As GSK3a has been shown to inhibit the Wnt signaling pathway, the inhibition of GSK3a activity by phosphorylation might suggest that Wnt signaling is part of the mechanism of action of ACSL 4 overexpression. The aberrant regulation of the Wnt signaling pathway is a prevalent theme in cancer biology. From early observations that Wnt overexpression could lead to malignant transformation of mouse mammary tissue to the most recent genetic discoveries gleaned from tumor genome sequencing, the Wnt pathway continues to evolve as a central mechanism in cancer biology. Results from RNA-Seq also show that ACSL4 overexpression causes a strong reduction in the expression of WIF1. The protein encoded by this gene inhibits Wnt proteins, which are extracellular signaling molecules playing a role in embryonic development. Mammary cancer is a prominent example involving the Wnt pathway, particularly cancers classified as basal-like or triple-negative $[29,30]$ which characteristically involve the expression of Wnt receptor FZD7 [31]. Accordingly, Yang et al. recently reported experiments in which knockdown of FZD7, in cell line models of triple-negative breast cancer, reduced the expression of Wnt target genes, inhibited tumorigenesis in vitro and greatly retarded the capacity of the MDA-MD-231 cell line to form tumors in mice [32]. These results suggest that Wnt ligands might drive certain breast cancers and are consistent with previous work from the Hynes laboratory [33]. In agreement with these data, ACSL4 overexpression increased the expression of WNT6 and WNT10A (Figure 1). The WNT6 gene is overexpressed in cervical cancer cell lines and strongly coexpressed with another family member, WNT10A, in a colorectal cancer cell line. WNT6 overexpression may play a key role in carcinogenesis and is clustered with WNT10A in chromosome 2q35 region. The Wnt pathway is also implicated in the activation of mTORC1 through TSC1/2. In our studies, Wnt signaling inhibited GSK3 $\beta$, which normally phosphorylates and promotes TSC2 activity, and ACSL4 overexpression produced the stimulation of GSK3 on Ser9, which suggests that this mechanism of mTORC1 activation is also used by ACSL4 [22]. As mentioned above, ACSL4 overexpression increases the phosphorylation of GSK3 $\alpha$ and $\beta$, and a requirement for ACSL4 has recently been demonstrated in dorsoventral pattering of zebrafish embryo [12] and embryogenesis and neurogenesis in Drosophila $[14,24]$. These results show that ACSL4 works through the inhibition of AKT-dependent GSK3 activity by increasing its phosphorylation. And, given the interplay between morphogenic signals in developing 
embryos, the interaction of these pathways might be expected in cancer. ACSL4 overexpression also stimulates the protein levels of growth factors and their receptors, such as the insulin-like growth factor binding protein (IGFBP2). Among genes involved in cell cycle control, ACSL4 decreases the level of the atalaxia telangiestasa (ATM) gene, a kinase that regulates cell cycle checkpoints by phosphorylating multiple proteins including histone $\mathrm{H} 2 \mathrm{AX}, \mathrm{CHK} 1$ and CHK2 kinases and p53. ATM is activated through auto- or transphosphorylation on Ser1981 and/or Ser1893 in response to DNA damage, particularly the induction of DNA double-strand breaks. ACSL4 also produces a substantial increase in cyclin-B1, the oncogen E3 ubiquitin protein ligase (MDM2), the eukaryotic translation factor $4 \mathrm{E}$ binding protein 1 (EEF2) and the GRB2-associated binding protein 2 (GAB2). In the energy area, genes regulated are the acetyl-CoA-carboxylase alpha and beta $(A C C)$ and the succinate dehydrogenase complex subunit a flavoprotein $(S D H A)$, a part of the respiratory chain. ACC participate in fatty acid synthesis and oxidation and are phosphorylated by AMP-activated protein kinase (AMPK) on Ser79 to inhibit their activity. ACSL4 overexpression decreases the activity of AMPK and thus decreases the phosphorylation of ACC. Finally, another gene increased by ACSL4 is the disheveled segment polarity protein 3 (DVL3), a member of a multi-gene family which bears strong similarities with the Drosophila disheveled gene, which in turn encodes a cytoplasmic phosphoprotein that regulates cell proliferation. The idea of personalized medicine and molecular profiling for prognostic tests has led to a plethora of studies in the past 10 years, in search for genetic determinants of metastasic breast cancer. Such studies have identified gene sets, or "signatures", whose expression in primary tumors is associated with higher risk of metastasis and poor disease outcome for the patients. Current views on cancer cell mutations hold that there are two different types: driver mutations, which are behind cancer growth because they give tumor cells a growth advantage, and passenger mutations, which are just along for the ride. It has been suggested that ACSL4 overexpression is led by a driver mutation $[18,34]$; however, as it is capable per se of changing cancer cell phenotypes, ACSL4 overexpression may be thought of as a backseat driver factor which generates changes in gene expression and signaling pathways toward a highly aggressive phenotype, and which acts in addition to passenger mutations when the driver gene is mutated. In summary, this study derives an ACSL4 overexpression gene and functional proteomic signature which might reveal important information about novel mediators of breast cancer cell aggressiveness. Here we report that ACSL4 overexpression can trigger several different mechanisms to regulate the aggressiveness of breast cancer cells, including the pathways stimulated by growth factors, nutrients, cytokines and changes in energy metabolism. The major findings of the present study are: (a) ACSL4 overexpression induces changes in genes associated with tumorigenesis-related biofunctions; (b) the four biofunctions with the highest activation $\mathrm{z}$-scores are: cell movement, growth and proliferation, protein and cell assembly and organization; (c) the inhibition of ACSL4 expression completely abolishes the changes observed in protein expression and phosphorylationdephosphorylation, which demonstrates the specificity of ACSL4 function; (d) since ACSL4 is per se capable of changing cancer cell phenotype, this protein overexpression may be thought of as a backseat driver factor which generates changes in gene expression and signaling pathways toward a highly aggressive phenotype; e) as ACSL4 has been related to colon and hepatocellular carcinoma, besides breast carcinoma, the present findings suggest novel mediators, specifically for combined pharmacological treatment toward tumor growth inhibition. Altogether, the present results open the possibility to use the inhibition of ACSL4 as a therapeutic tool in combination with agents targeting key molecular elements involved in breast cancer. In addition, ACSL 4 could be used as a predictive marker that may provide the basis for patient therapy.

\section{Acknowledgements}

We thank Cristina Paz for her critical reading of the manuscript and Maria M. Rancez for providing language help and writing assistance. This work was supported by CONICET (PIP 2012-2014 - COD 11220110100485), Podesta; UBA (UBACYT 2011-2014 - 20020100100 849), Podesta.

\section{References}

1. Jemal A, Siegel R, Ward E, Murray T, Xu J, et al. (2007) Cancer statistics. CA Cancer J Clin 571: 43-66.

2. Monaco ME, Creighton CJ, Lee P, Zou X, Topham MK, et al. (2010) Expression of Long-chain Fatty Acyl-CoA Synthetase 4 in Breast and Prostate Cancers Is Associated with Sex Steroid Hormone Receptor Negativity. Transl Oncol 32 91-98.

3. Maloberti PM, Duarte AB, Orlando UD, Pasqualini ME, Solano AR, et al. (2010) Functional interaction between acyl-CoA synthetase 4, lipooxygenases and cyclooxygenase- 2 in the aggressive phenotype of breast cancer cells. PLoS One 511: e15540.

4. Orlando UD, Garona J, Ripoll GV, Maloberti PM, Solano AR, et al. (2012) The functional interaction between Acyl-CoA synthetase 4, 5-lipooxygenase and cyclooxygenase-2 controls tumor growth: a novel therapeutic target. PLoS One 77: e40794.

5. Wu X, Li Y, Wang J, Wen X, Marcus MT, et al. (2013) Long chain fatty Acyl-CoA synthetase 4 is a biomarker for and mediator of hormone resistance in human breast cancer. PLoS One 810: e77060.

6. Kang MJ, Fujino T, Sasano H, Minekura H, Yabuki N, et al. (1997) A nove arachidonate-preferring acyl-CoA synthetase is present in steroidogenic cells of the rat adrenal, ovary, and testis. Proc Natl Acad Sci U S A 947: 2880-2884.

7. Soupene E, Kuypers FA (2008) Mammalian long-chain acyl-CoA synthetases Exp Biol Med (Maywood) 2335: 507-521.

8. Watkins PA, Ellis JM (2012) Peroxisomal acyl-CoA synthetases. Biochim Biophys Acta 18229: 1411-1420.

9. Watkins PA (1997) Fatty acid activation. Prog Lipid Res 361: 55-83.

10. Li LO, Klett EL, Coleman RA (2010) Acyl-CoA synthesis, lipid metabolism and lipotoxicity. Biochim Biophys Acta 18013: 246-251.

11. Cao Y, Murphy KJ, McIntyre TM, Zimmerman GA, Prescott SM (2000) Expression of fatty acid-CoA ligase 4 during development and in brain. FEBS Lett 4672-3: 263-267.

12. Miyares RL, Stein C, Renisch B, Anderson JL, Hammerschmidt M, et al. (2013) Long-chain Acyl-CoA synthetase 4A regulates Smad activity and dorsoventral patterning in the zebrafish embryo. Dev Cell 276: 635-647.

13. Maloberti P, Castilla R, Castillo F, Maciel FC, Mendez CF, et al. (2005) Silencing the expression of mitochondrial acyl-CoA thioesterase I and acyl-CoA synthetase 4 inhibits hormone-induced steroidogenesis. Febs J 2727: 1804 1814

14. Y, Zhang Y, Gao Y, Zhao X, Wang Z (2011) Drosophila long-chain acyl-CoA synthetase acts like a gap gene in embryonic segmentation. Dev Biol 3532: 259-265.

15. Gazou A, Riess A, Grasshoff U, Schaferhoff K, Bonin M, et al. (2013) Xq22.3-q23 deletion including ACSL4 in a patient with intellectual disability. Am J Med Genet A 161A4: 860-864.

16. Modi HR, Basselin M, Taha AY, Li LO, Coleman RA, et al. (2013) Propylisopropylacetic acid (PIA), a constitutional isomer of valproic acid uncompetitively inhibits arachidonic acid acylation by rat acyl-CoA synthetase 4: a potential drug for bipolar disorder. Biochim Biophys Acta 18314: 880-886.

17. Sung YK, Hwang SY, Park MK, Bae HI, Kim WH, et al. (2003) Fatty acid-CoA ligase 4 is overexpressed in human hepatocellular carcinoma. Cancer Sci 945 $421-424$

18. Cao Y, Dave KB, Doan TP and Prescott SM (2001) Fatty acid CoA ligase 4 is up-regulated in colon adenocarcinoma. Cancer Res 6123: 8429-8434.

19. Jiang M, Huang O, Xie Z, Wu S, Zhang X, et al. (2014) A novel long non-coding RNA-ARA: adriamycin resistance-associated. Biochem Pharmacol 872: 254-283.

20. Database for Annotation, Visualization and Integrated Discovery (DAVID) http:// david.abcc.ncifcrf.gov.

21. Ingenuity Pathways Analysis (IPA). http://www.ingenuity.com. 
Citation: Castillo AF, Orlando UD, Lopez P, Solano AR, Maloberti PM, et al. (2015) Gene Expression Profile and Signaling Pathways in MCF-7 Breast Cancer Cells Mediated by Acyl-CoA Synthetase 4 Overexpression. Transcriptomics 3: 120. doi:10.4172/2329-8936.1000120

22. Orlando UD, Castillo AF, Dattilo MA, Solano AR, Maloberti PM, et al. (2015) Acyl-CoA synthetase- 4 , a new regulator of $\mathrm{mTOR}$ and a potential therapeutic target for enhanced estrogen receptor function in receptor-positive and -negative breast cancer. Oncotarget In press.

23. Pignatelli M, Serras F, Moya A, Guigo R, Corominas M (2009) CROC: finding chromosomal clusters in eukaryotic genomes. Bioinformatics 2512: 1552-1553.

24. Liu Z, Huang Y, Hu W, Huang S, Wang Q, et al. (2014) dAcsl, the Drosophila ortholog of acyl-CoA synthetase long-chain family member 3 and 4 , inhibits synapse growth by attenuating bone morphogenetic protein signaling via endocytic recycling. J Neurosci 348: 2785-2796.

25. Endo Y, Toyama T, Takahashi S, Yoshimoto N, Iwasa M, et al. (2013) miR-1290 and its potential targets are associated with characteristics of estrogen receptor alpha-positive breast cancer. Endocr Relat Cancer 201: 91-102.

26. Johnson CD, Esquela-Kerscher A, Stefani G, Byrom M, Kelnar K, et al. (2007) The let-7 microRNA represses cell proliferation pathways in human cells. Cancer Res 6716: 7713-7722.

27. Yamaguchi H, Takeo Y, Yoshida S, Kouchi Z, Nakamura Y, et al. (2009) Lipid rafts and caveolin-1 are required for invadopodia formation and extracellular matrix degradation by human breast cancer cells. Cancer Res 6922: 8594 8602.
28. Golubovskaya VM (2010) Focal adhesion kinase as a cancer therapy target. Anticancer Agents Med Chem 1010: 735-741.

29. Geyer FC, Lacroix-Triki M, Savage K, Arnedos M, Lambros MB, et al. (2011) beta-Catenin pathway activation in breast cancer is associated with triplenegative phenotype but not with CTNNB1 mutation. Mod Pathol 242: 209-231.

30. Khramtsov Al, Khramtsova GF, Tretiakova M, Huo D, Olopade OI, et al. (2010) Wnt/beta-catenin pathway activation is enriched in basal-like breast cancers and predicts poor outcome. Am J Pathol 1766: 2911-2920.

31. Sorlie T, Tibshirani R, Parker J, Hastie T, Marron JS, et al. (2003) Repeated observation of breast tumor subtypes in independent gene expression data sets. Proc Natl Acad Sci U S A 10014: 8418-8423.

32. Yang L, Wu X, Wang Y, Zhang K, Wu J, et al. (2011) FZD7 has a critical role in cell proliferation in triple negative breast cancer. Oncogene 3043: 4437-4446.

33. Matsuda Y, Schlange T, Oakeley EJ, Boulay A, Hynes NE (2009) WNT signaling enhances breast cancer cell motility and blockade of the WNT pathway by SFRP1 suppresses MDA-MB-231 xenograft growth. Breast Cancer Res 113: R32.

34. Kaller M, Liffers ST, Oeljeklaus S, Kuhlmann K, Roh S, et al. (2011) Genomewide characterization of miR-34a induced changes in protein and mRNA expression by a combined pulsed SILAC and micro-array analysis. Mol Cell Proteomics.
Citation: Castillo AF, Orlando UD, Lopez P, Solano AR, Maloberti PM, et al. (2015) Gene Expression Profile and Signaling Pathways in MCF-7 Breast Cancer Cells Mediated by Acyl-Coa Synthetase 4 Overexpression. Transcriptomics 3: 120 . doi:10.4172/2329-8936.1000120
Submit your next manuscript and get advantages of OMICS Group submissions

\section{Unique features:}

- Increased global visibility of articles through worldwide distribution and indexing

- Showcasing recent research output in a timely and updated manner

- Special issues on the current trends of scientific research

Special features:

- 700 Open Access Journals

50,000 editorial team

50,000 editorial team

Quality and quick editorial, review and publication processing

Indexing at PubMed (partial), Scopus, DOAJ, EBSCO, Index Copernicus and Google Scholar etc Sharing Option: Social Networking Enabled

Authors, Reviewers and Editors rewarded with online Scientific Credits

Better discount for your subsequent articles

Submit your manuscript at: http://scholarscentral.com/ 
Table S1. Detailed list of genes regulated by ACSL4 within the top three biofunctions by IPA.

\begin{tabular}{|c|c|c|c|c|c|c|}
\hline Category & $\begin{array}{l}\text { Diseases or } \\
\text { Functions } \\
\text { Annotation }\end{array}$ & $p$-value & $\begin{array}{l}\text { Predicted } \\
\text { Activation } \\
\text { State }\end{array}$ & $\begin{array}{c}\text { Activation } \\
\text { z-score }\end{array}$ & Molecules & \# Molecules \\
\hline
\end{tabular}

ABCC4, ACSL4, ADARB1, ADORA1, ANXA3, APOE, AREG/AREGB, ARHGAP24, ARHGAP8/PRR5-ARHGAP8, ASCL1, B4GALT1, BAI1, BMP7, BSG, BTC, CADPS2, CAMK1D, CCR1, CD82, CDKN2A, CEBPA, CELF3, CHRD, CHST10, CMTM8, CNTNAP2, COL18A1, CSF2RA, CTGF, CTNND2, CTSL, CXCL17, DCDC2, DDX58, DGCR6L, DIAPH2, DLX1, DLX2, DPYSL2, DYRK1B, EDN2, EFNA1, EFNB3, EGFL7, EHF, EPHB4, ERBB2, ERRFI1, ETV4, ETV6, F2RL1, FGFR1, FGFR4, FHL1, FLT3LG, FOS, FOXO4, FURIN, GATA6, GCNT1, GGT5, GLIPR2, GNAl1, GPR173, GPR56, GRB7, GRN, GUCY1A3, HCAR2, HLA-G, HPGD, HSPA1A/HSPA1B, HSPB1, ID2, ID3, IGFBP5, IGSF8, IL20, IL24, IL6R, IL6ST, INSR, IRF6, IRF7, ITGA2, ITGB4, KLF2, LAMB1, let-7,

Cellular Movement cell movement

Increased

4.685 MAFB, MAPK10, MARCKS, MARK1, MATK, MGLL, mir-29, MSR1, MT-ND1, PLD1, PODXL, PPP3CC, PREX1, PRMT2, PTGDR2, PTTG1, QPCT, RAP1GAP, PLD1, PODXL, PPP3CC, PREX1, PRMT2, PTGDR2, PTTG1, QPCT, RAP1GAP,
RAPGEF1, RAPGEF2, REPS2, RET, RHOBTB2, RHOU, RNF144A, RPS6KA1, S100A1, S100A12, S100A7, S100A8, S100A9, S100P, SCARB1, SCPEP1, SDC1, SH3PXD2B, SHC4, SKI, SLPI, SOCS2, SORBS3, SORD, SPHK1, SPRY4, ST6GAL1, STARD13, SYK, TACSTD2, TAZ, TENC1, TERC, TFAP2C TGFB1I1, TGFB2, THBD, THRA, TM4SF1, TMSB10/TMSB4X, TNFRSF11B, TNFRSF21, TNFSF9, TNS1, TP73, TPT1, TRPC1, TSPO, VASH1, VAV1, VIPR1, VIPR2, WAS, WNT10B, ZNF217, ZSCAN1

ABCC4, ACSL4, ADARB1, ADORA1, ANXA3, APOE, AREG/AREGB, ARHGAP24, ARHGAP8/PRR5-ARHGAP8, ASCL1, B4GALT1, BAI1, BMP7, BSG, BTC, CADPS2, CAMK1D, CCR1, CD82, CDKN2A, CEBPA, CHRD, CHST10, CMTM8, CNTNAP2, COL18A1, CSF2RA, CTGF, CTSL, CXCL17, DCDC2, DDX58, DGCR6L, DIAPH2, DLX1, DLX2, DPYSL2, DYRK1B, EDN2, EFNA1, EFNB3, EGFL7, EHF, EPHB4, ERBB2, ERRFI1, ETV4, ETV6, F2RL1, FGFR1, FHL1, FLT3LG, FOXO4, FURIN, GATA6, GCNT1, GGT5, GLIPR2, GNAl1, GPR173, GPR56, GRB7, GRN, GUCY1A3, HCAR2, HLA-G, HPGD, HSPA1A/HSPA1B, HSPB1, ID2, ID3, IGFBP5, IGSF8, IL20, IL24, IL6R, IL6ST, INSR, IRF6, IRF7, ITGA2, ITGB4, KLF2, LAMB1, let-7, MAFB, MAPK10, MARCKS, MARK1, MATK, MGLL, mir-29, MSR1, MT-ND1, MZF1, NDRG1, NDST1, NFIX, NMU, NOD1, NOTCH2, NQO1, NTN1, NTRK3, ONECUT1, P2RX4, PARP9, PDCD4, PDE4D, PDE4DIP, PGR, PLD1, PODXL, PREX1, PRMT2, PTGDR2, PTTG1, QPCT, RAP1GAP, RAPGEF1, RAPGEF2, REPS2, RET, RHOBTB2, RHOU, RNF144A, S100A12, S100A7, S100A8, S100A9, S100P, SCARB1, SCPEP1, SDC1, SH3PXD2B, SHC4, SLPI, SORBS3, SPHK1, SPRY4, ST6GAL1, SYK, TACSTD2, TAZ, TENC1, TERC, TFAP2C, TGFB1I1, TGFB2, THBD, TM4SF1, TMSB10/TMSB4X, TNFRSF11B, TNFRSF21, TNFSF9, 
TNS1, TP73, TPT1, TRPC1, TSPO, VASH1, VAV1, VIPR1, WAS, WNT10B, ZSCAN1

ABCC4, ABTB1, ACHE, ACPP, ACSL4, ACSL6, ADAMTS9, ADARB1, ADC ADIPOR2, ADORA1, AFAP1L2, AGTRAP, ANO3, ANTXR1, ANXA6, APOD, APOE, AREG/AREGB, ARHGAP24, ARHGEF2, ARL2BP, ASAH2, ASCL1, ASCL2, ATP8A2, ATR, B4GALT1, B4GALT6, B4GALT7, BAI1, BIK, BMP7, BSG, BST2, BTC, BTG3, C1QL4, C8orf4, CACFD1, CACUL1, CBX2, CCNG2, CCR1, CD82, CDKN2A, CEBPA, CHRD, CHST11, CISH, COL18A1, COL6A2, CSF2RA, CTGF, CTNND2, CTSL, CUX2, DDX58, DEGS2, DIRAS1, DLX2, DLX4, DOK3, DOT1L, DUSP2, DYRK1B, E2F8, EDN2, EFNA1, EFNB3, EHF, EIF4B, ELF5, ENPEP, EPHB4, EPHB6, ERBB2, ERRFI1, ETV6, EXOSC4, F2RL1, FBXO9, FGFR1, FGFR4, FHL1, FLT3LG, FOS, FOXD2, FOXO4, FOXP2, FSTL3, FURIN G3BP1, GABARAPL1, GABRP, GATA6, GCNT1, GGT5, GLUL, GNAI1, GOLM1, GPR56, GPRC5C, GPX2, GRB7, GRM4, GRN, GSX2, GTPBP1, HDAC4 HDAC5, HINT1, HIST1H2BH/HIST1H2BO, HLA-E, HOXA5, HPGD, HR, HS6ST2, HSPA1A/HSPA1B, HSPA8, ID2, ID3, IFLTD1, IGFBP5, IL20, IL24, IL6R, IL6ST, INHA, INPP5K, INSIG1, INSR, IRF6, ISG15, ISG20, ITGA2, ITGB4, KCND3, KIF1A, KIF26A, KLF11, KLF13, KLF2, KLF6, LAMB1, LDLRAP1, let-7, LMO1,

Cellular Growth and Proliferation proliferation

of cells
2.04E-06

Increased
2.390

LMO2, LRRN1, LSMD1, LTBP1, MAFA, MAFB, MAFF, MAGED4/MAGED4B,

MANF, MAP3K3, MAPK10, MATK, MINPP1, mir-25, mir-29, MSH3, MSMB, MSR1, MT2A, MZF1, NAB1, NCOA4, NDRG1, NEIL1, NEURL, NFIX, NOTCH2, NPDC1, NQO1, NR3C1, NTN1, NTRK3, OAS3, OGFR, OPTN, PALM, PARP10, PARP14, PDCD4, PDE4D, PDZK1, PERP, PGR, PHF6, PLD1, POR, PPT1, PRICKLE2, PRKAR1B, PSCA, PTCH1, PTPN22, PTTG1, QPCT, RAP1GAP, RAPGEF1, RAPGEF2, RASL10A, RBM38, RET, RHOBTB2, RHOU, RAPGEF1, RAPGEF2, RASL10A, RBM38, RET, RHOBTB2, RHOU,
RNASEH2B, RPS6KA1, RRM2, RTKN, RTN4R, RYK, S100A1, S100A13, S100A7, S100A8, S100A9, S100P, SCARB1, SCPEP1, SCUBE3, SDC1, SH3GL3, SIX2, SKI, SLC19A1, SLC25A4, SLC25A6, SLC26A2, SLPI, SMAD6, SNAI3, SOCS2, SOS1, SOX4, SP110, SP6, SPHK1, SPRY4, ST5, ST6GAL1, STARD10, STARD13, STAT2, SUV39H1, SYK, TACC1, TACSTD2, TAGLN, TAZ, TEAD4, TENC1, TERC, TFAP2C, TGFB1I1, TGFB2, THBD, THG1L, THRA, TMEM2, TMSB10/TMSB4X, TNFRSF11B, TNFRSF21, TNFSF9, TOB2, TP53I11, TP73, TPM2, TPT1, TRADD, TRIM21, TRPC1, TSPO, TXNIP, TXNRD2, UBE2L6, UCHL1, USP18, VANGL1, VASH1, VAV1, VDAC1, VIPR1, WAS, WNT10B, WNT6, WNT9A, YPEL3, ZNF217, ZSCAN1, ZSCAN18 
Figure S1. Chromosome distribution patterns of differentially expressed genes and gene clusters of ACSL4-overexpressing cells.

The analysis was performed with the CROC program (http://metagenomics.uv.es/CROC) and results were corrected by the Benjamini \& Hochberg multiple test correction method. The minimum number of genes per cluster was 3 and the reference type of statistical analysis was by chromosome.

$\gg$ Stats

\begin{tabular}{|l|l|}
\hline User genes found in reference genome & 960 \\
\hline Number of Unknown genes & 1183 \\
\hline Number of clusters found & 52 \\
\hline Total number of genes in clusters & 508 \\
\hline Number of user genes in clusters & 181 \\
\hline
\end{tabular}

\section{$\gg$ Chromosomes}

Chrom Clusters Genes In user set

\begin{tabular}{|c|c|c|c|c|}
\hline chr1 & 8 & 2107 & 119 & 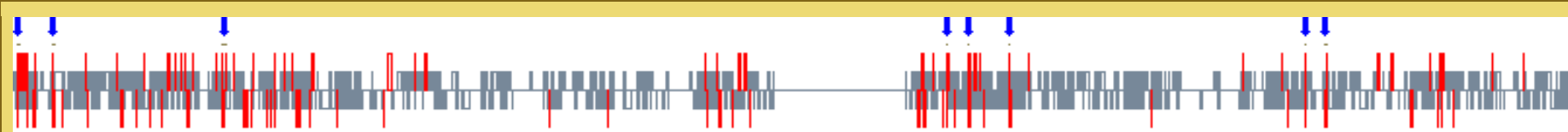 \\
\hline chr10 & 1 & 812 & 29 & 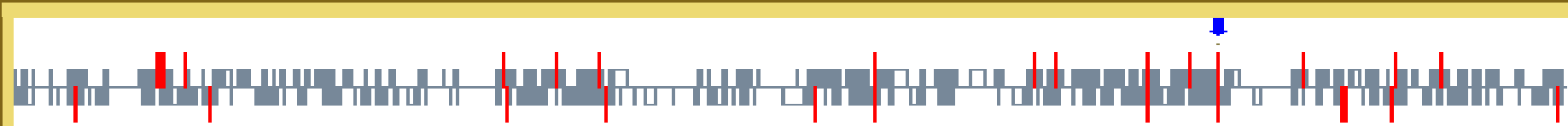 \\
\hline chr11 & 3 & 1364 & 53 & 2. \\
\hline chr12 & 5 & 1056 & 58 & 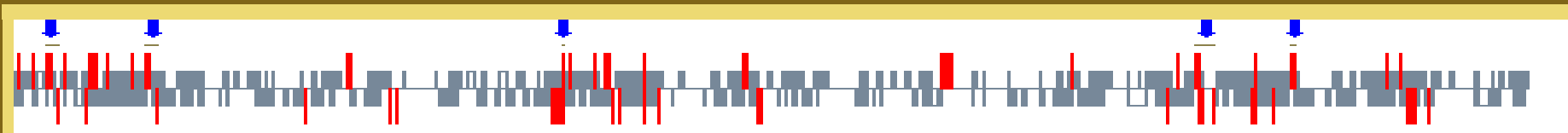 \\
\hline
\end{tabular}




\begin{tabular}{|c|c|c|c|c|}
\hline chr15 & 1 & 655 & 31 & 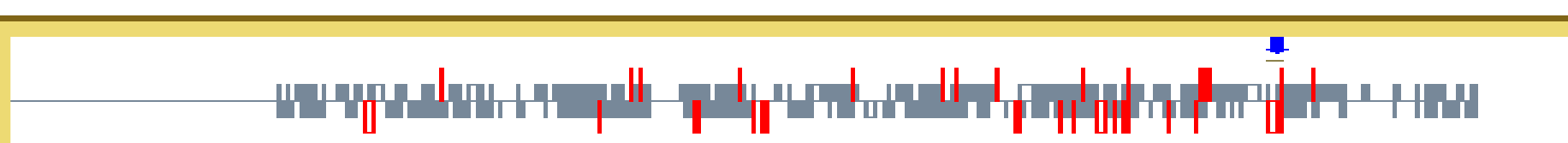 \\
\hline chr16 & 2 & 900 & 27 & 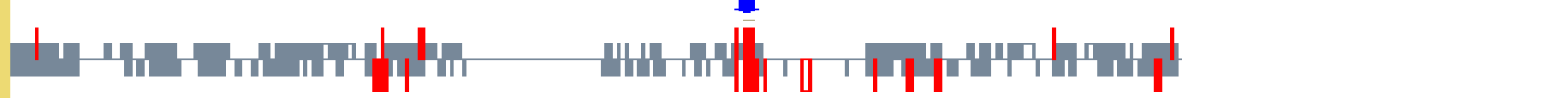 \\
\hline chr17 & 4 & 1230 & 65 & Ill \\
\hline chr19 & 2 & 1453 & 58 & | \\
\hline $\mathrm{chr} 2$ & 3 & 1356 & 78 & III) \\
\hline chr20 & 4 & 577 & 28 & 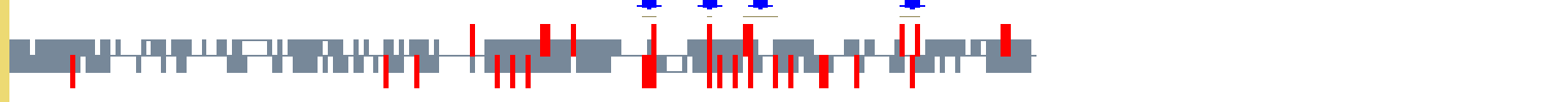 \\
\hline chr22 & 1 & 538 & 29 & 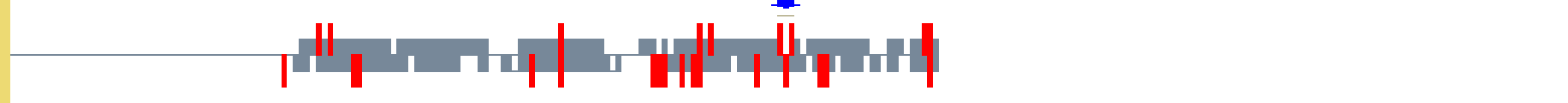 \\
\hline chr3 & 3 & 1096 & 43 & 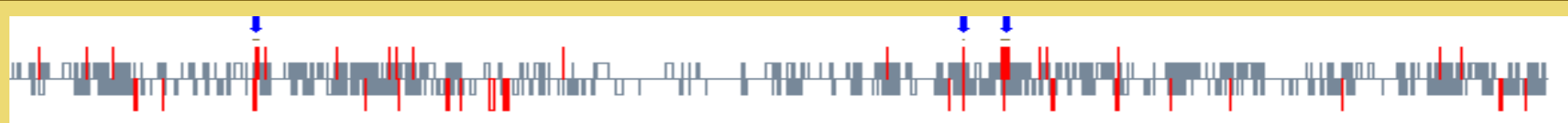 \\
\hline chr4 & 3 & 777 & 48 & 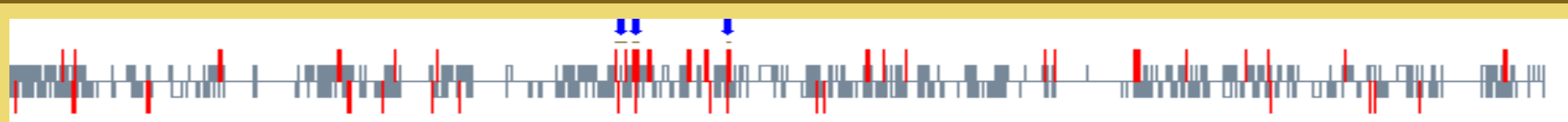 \\
\hline
\end{tabular}




\begin{tabular}{|c|c|c|c|c|}
\hline chr5 & 3 & 893 & 51 & 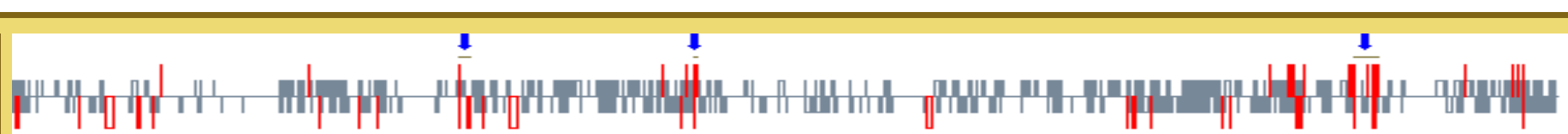 \\
\hline chr6 & 3 & 1087 & 49 & 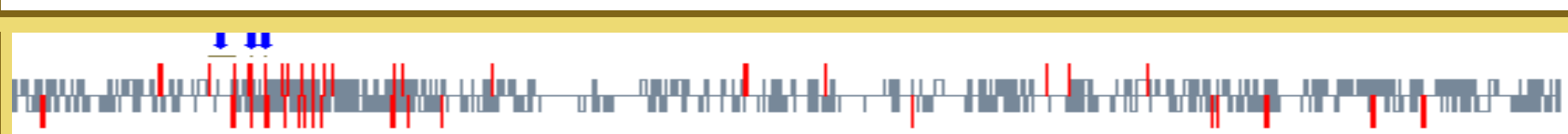 \\
\hline chr7 & 2 & 1024 & 46 & 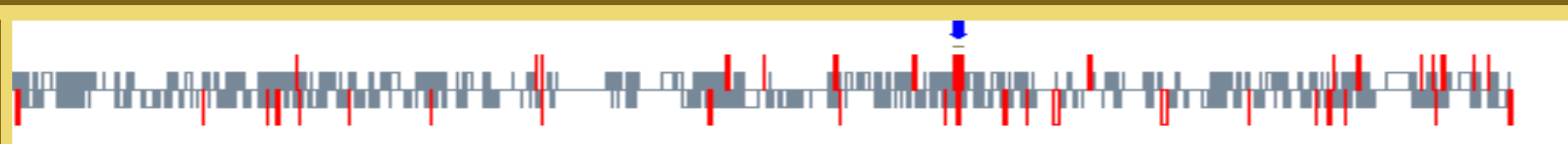 \\
\hline chro & 1 & 732 & 32 & 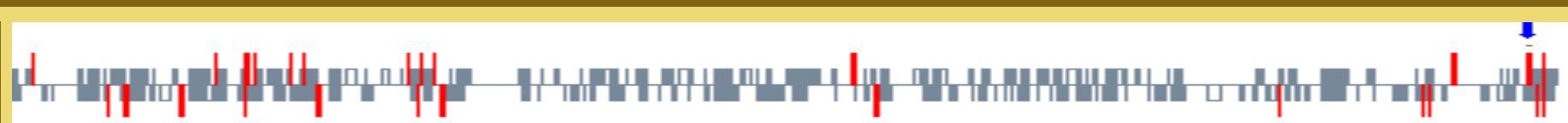 \\
\hline chr9 & 3 & 848 & 48 & 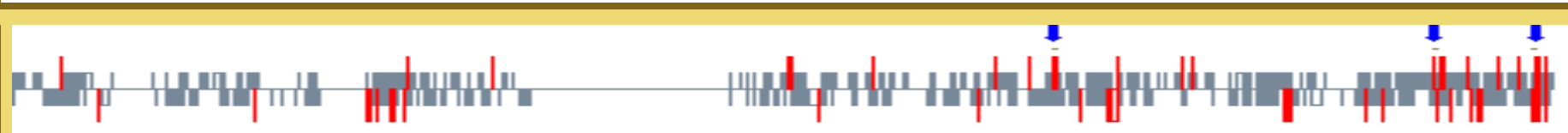 \\
\hline
\end{tabular}

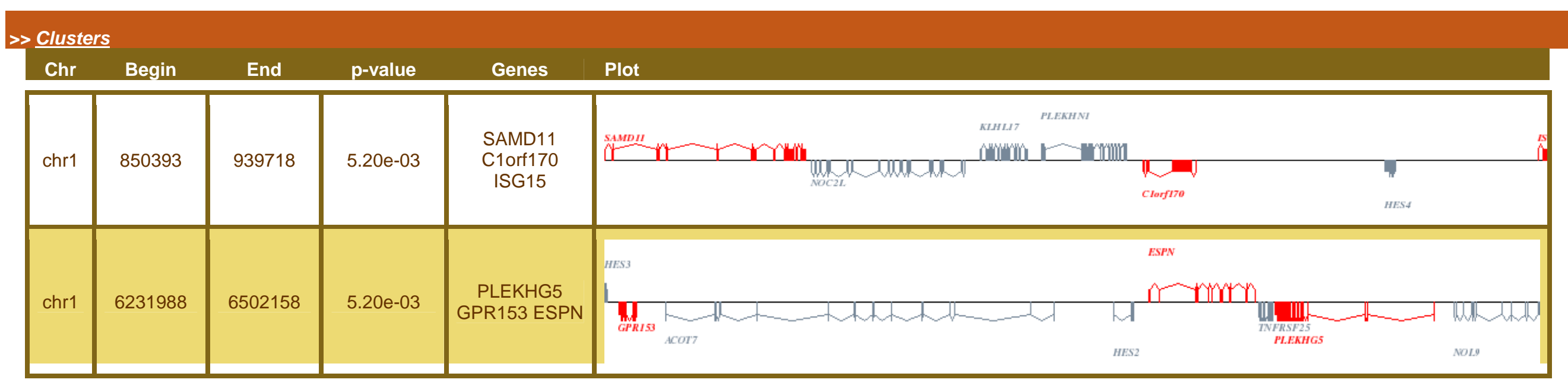




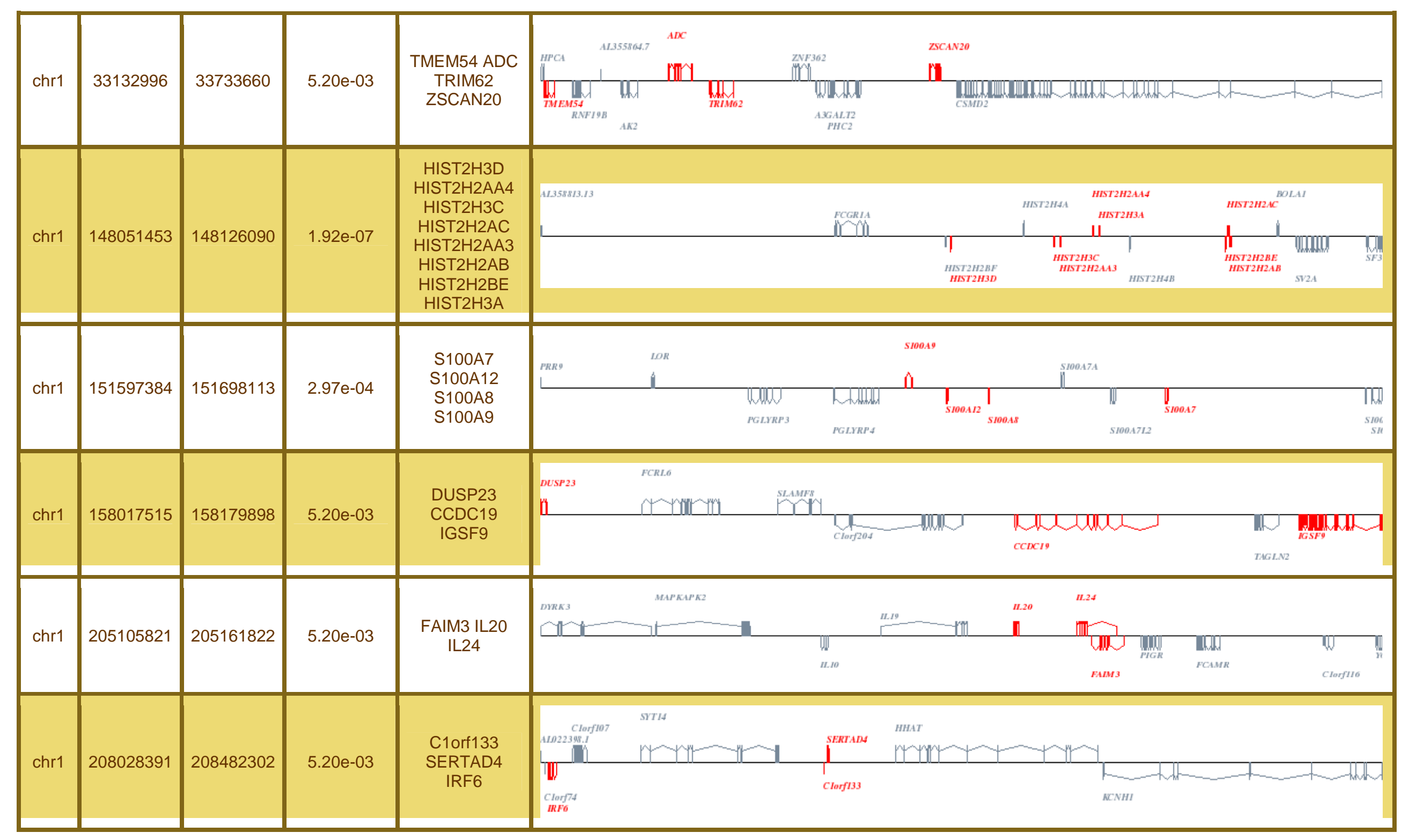




\begin{tabular}{|c|c|c|c|c|c|}
\hline chr10 & 105148174 & 105340116 & $1.30 \mathrm{e}-03$ & $\begin{array}{l}\text { NEURL } \\
\text { PDCD11 } \\
\text { CALHM2 }\end{array}$ & USMGS \\
\hline chr11 & 301317 & 480579 & $1.74 \mathrm{e}-03$ & $\begin{array}{l}\text { IFITM1 IFITM3 } \\
\text { PTDSS2 }\end{array}$ & IFITM 3 IFITMI \\
\hline chr11 & 44572789 & 45789459 & $1.74 \mathrm{e}-03$ & $\begin{array}{l}\text { SYT13 } \\
\text { TP53I11 } \\
\text { SLC35C1 } \\
\text { CD82 }\end{array}$ & WLXA \\
\hline chr11 & 120828251 & 122437242 & $1.74 e-03$ & $\begin{array}{c}\text { SORL1 } \\
\text { C11orf63 } \\
\text { HSPA8 }\end{array}$ & СRASH \\
\hline chr12 & 2974194 & 3809442 & 4.71e-03 & $\begin{array}{c}\text { TEAD4 } \\
\text { TSPAN9 } \\
\text { PARP11 }\end{array}$ & 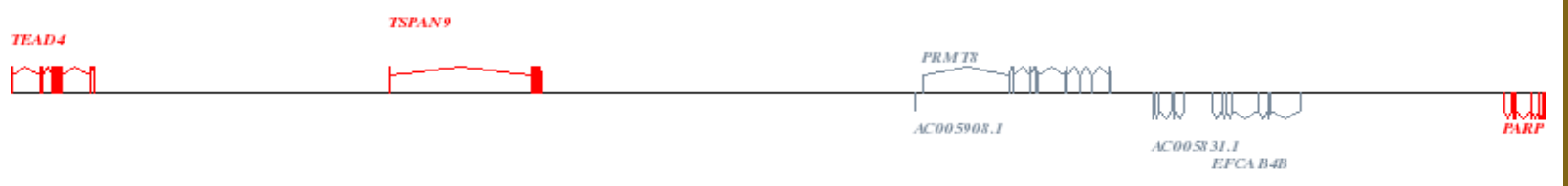 \\
\hline chr12 & 11694329 & 12565299 & $4.71 e-03$ & $\begin{array}{c}\text { ETV6 } \\
\text { MANSC1 } \\
\text { DUSP16 }\end{array}$ & 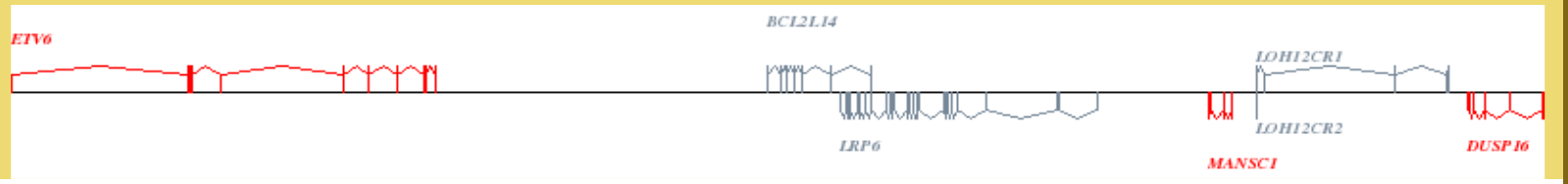 \\
\hline chr12 & 47975251 & 48031549 & $4.71 e-03$ & $\begin{array}{c}\text { DNAJC22 } \\
\text { PRPH C1QL4 }\end{array}$ & $\prod_{\text {TUAAIB }} \prod_{\text {TUBALA }}$ \\
\hline
\end{tabular}




\begin{tabular}{|c|c|c|c|c|c|}
\hline chr12 & 103375320 & 105056561 & $4.71 e-03$ & $\begin{array}{c}\text { CHST11 } \\
\text { SLC41A2 } \\
\text { NUAK1 }\end{array}$ & CHSTH \\
\hline chr12 & 111829228 & 111932669 & $4.71 e-03$ & $\begin{array}{c}\text { OAS2 OAS1 } \\
\text { OAS3 }\end{array}$ & 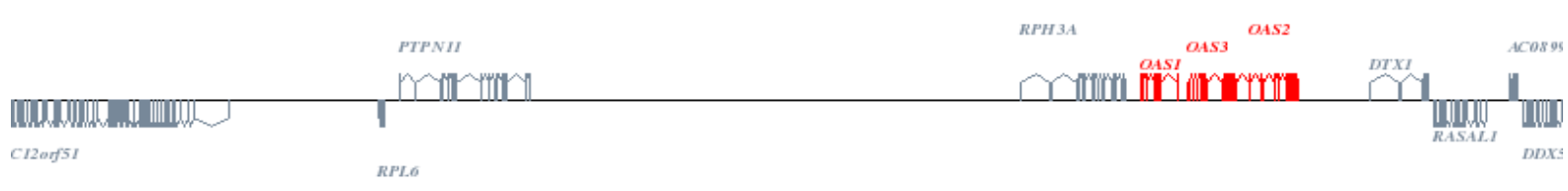 \\
\hline chr15 & 86221173 & 86999763 & $2.96 e-03$ & $\begin{array}{l}\text { NTRK3 DET1 } \\
\text { ISG20 }\end{array}$ & UIR \\
\hline chr16 & 55702156 & 55875953 & $7.80 \mathrm{e}-04$ & $\begin{array}{c}\text { ARL2BP } \\
\text { CPNE2 PLLP }\end{array}$ & 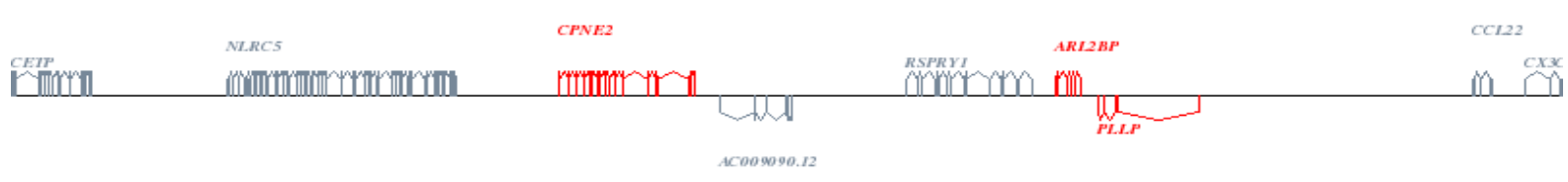 \\
\hline chr16 & 56104157 & 56389656 & $7.80 e-04$ & $\begin{array}{l}\text { CCDC102A } \\
\text { GPR56 KIFC3 }\end{array}$ & $\operatorname{limDCIO2A}_{\text {CCDARIA }}^{\text {GPRSG }}$ \\
\hline chr17 & 39741622 & 39936264 & $4.24 e-03$ & $\begin{array}{l}\text { RUNDC3A } \\
\text { GRN } \\
\text { GPATCH8 }\end{array}$ & 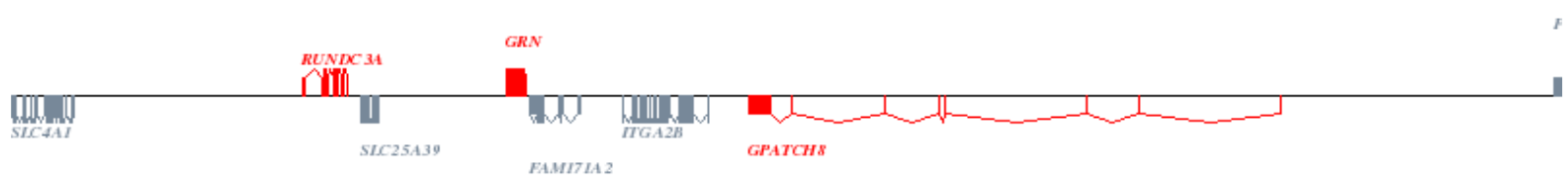 \\
\hline chr17 & 40655275 & 40915633 & $4.24 e-03$ & $\begin{array}{l}\text { ARHGAP27 } \\
\text { FMNL1 } \\
\text { PLEKHM1 }\end{array}$ & $\stackrel{\text { FMNLI }}{\text { HEXIM2 }}$ \\
\hline chr17 & 45401832 & 45557322 & $4.24 \mathrm{e}-03$ & $\begin{array}{l}\text { SAMD14 DLX4 } \\
\text { PDK2 }\end{array}$ & 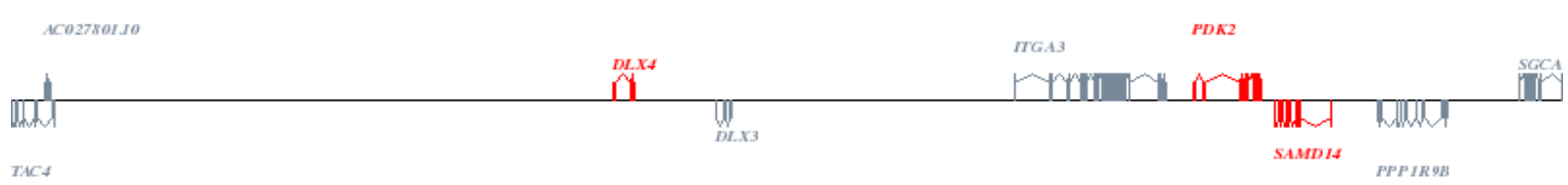 \\
\hline
\end{tabular}




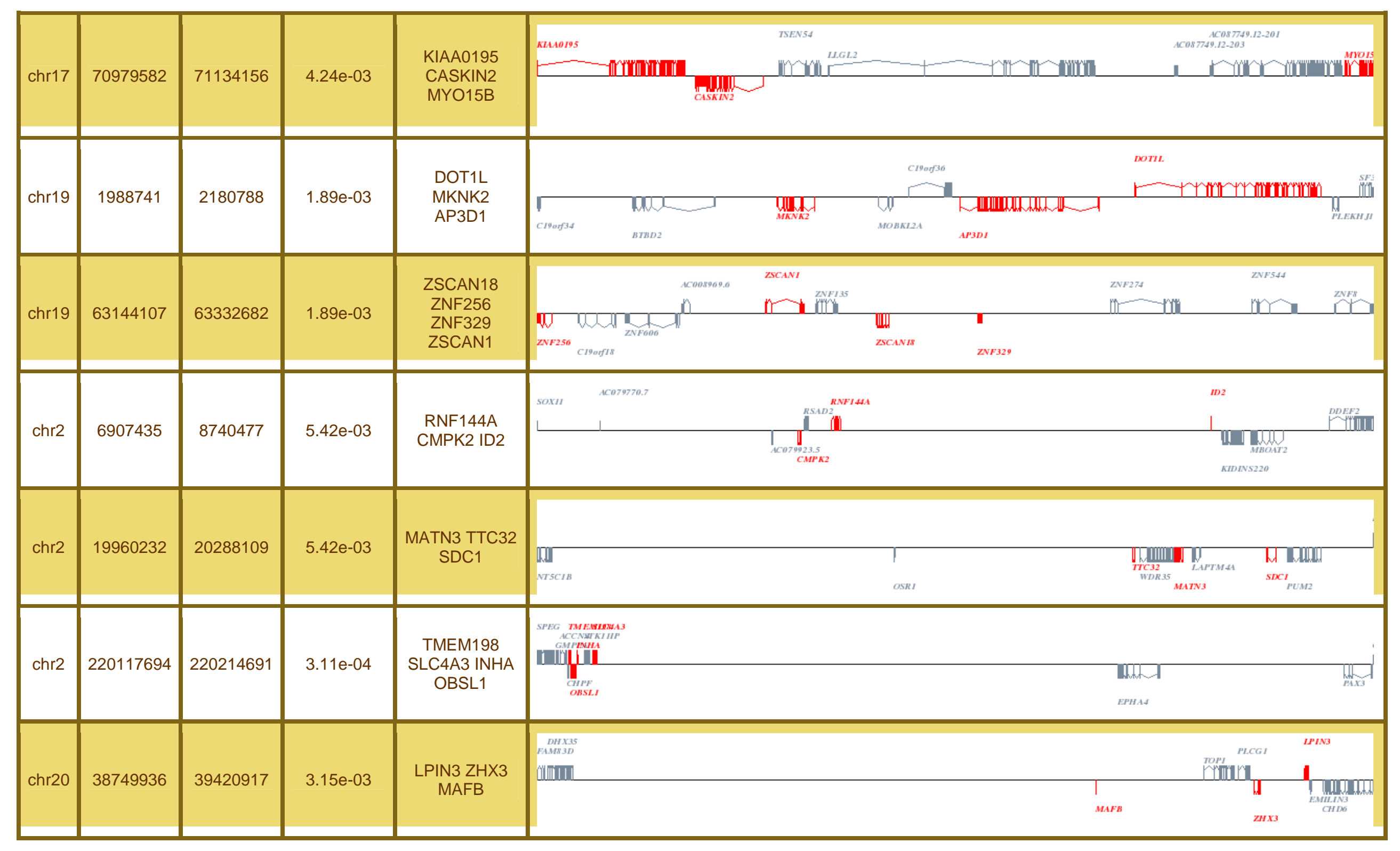




\begin{tabular}{|c|c|c|c|c|c|}
\hline chr20 & 42676612 & 42872326 & $3.15 e-03$ & $\begin{array}{c}\text { KCNK15 PKIG } \\
\text { RIMS4 }\end{array}$ & 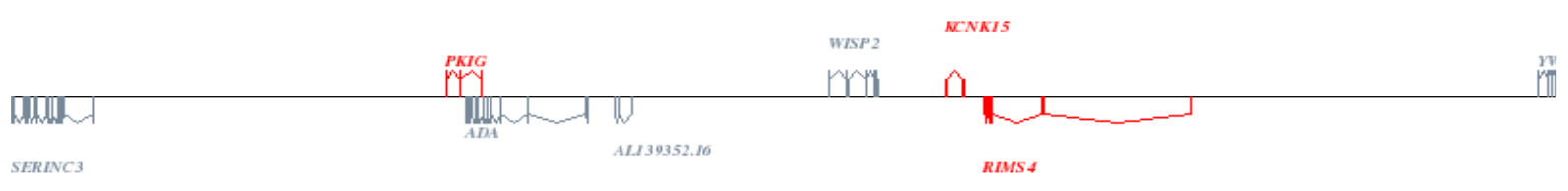 \\
\hline chr20 & 45040678 & 46877804 & $3.15 e-03$ & $\begin{array}{c}\text { EYA2 } \\
\text { ZMYND8 } \\
\text { PREX1 }\end{array}$ & $\sum_{I P S B R K}^{\text {SICZAIO }}$ \\
\hline chr20 & 54638008 & 55416305 & $3.15 e-03$ & $\begin{array}{c}\text { RBM38 } \\
\text { TFAP2C BMP7 }\end{array}$ & $\operatorname{mintant}_{\text {BMP }}$ \\
\hline chr22 & 41226621 & 41889018 & $4.27 e-03$ & $\begin{array}{l}\text { TSPO SERHL } \\
\text { SERHL2 } \\
\text { A4GALT BIK }\end{array}$ & $\underbrace{\text { SERHL.2 }}_{\substack{\text { SERHL } \\
\text { SRPAA }}}$ \\
\hline chr3 & 31678571 & 32386460 & $1.77 e-03$ & $\begin{array}{l}\text { OSBPL10 } \\
\text { ZNF860 } \\
\text { CMTM8 }\end{array}$ & TGFAR2 \\
\hline chr3 & 123729904 & 123930131 & $1.77 e-03$ & $\begin{array}{l}\text { PARP15 } \\
\text { PARP14 } \\
\text { PARP9 }\end{array}$ & PAMIGZ2A \\
\hline chr3 & 128867472 & 129609789 & $1.77 e-03$ & $\begin{array}{c}\text { ABTB1 MGLL } \\
\text { EEFSEC }\end{array}$ & 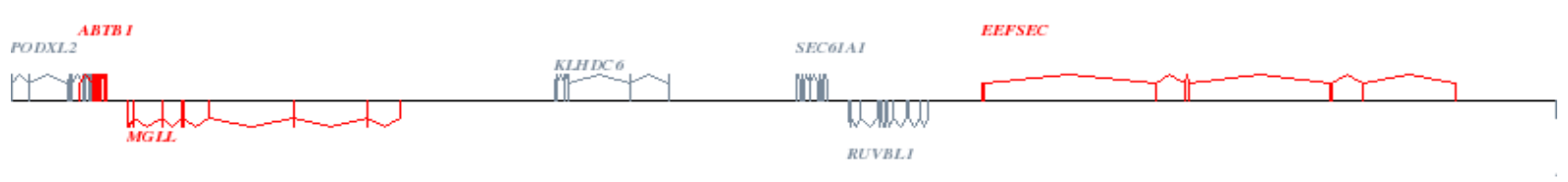 \\
\hline chr4 & 75529927 & 76708670 & $3.93 e-04$ & $\begin{array}{l}\text { BTC AREGB } \\
\text { C4orf26 AREG }\end{array}$ & $\prod_{C X C L 2}$ \\
\hline
\end{tabular}




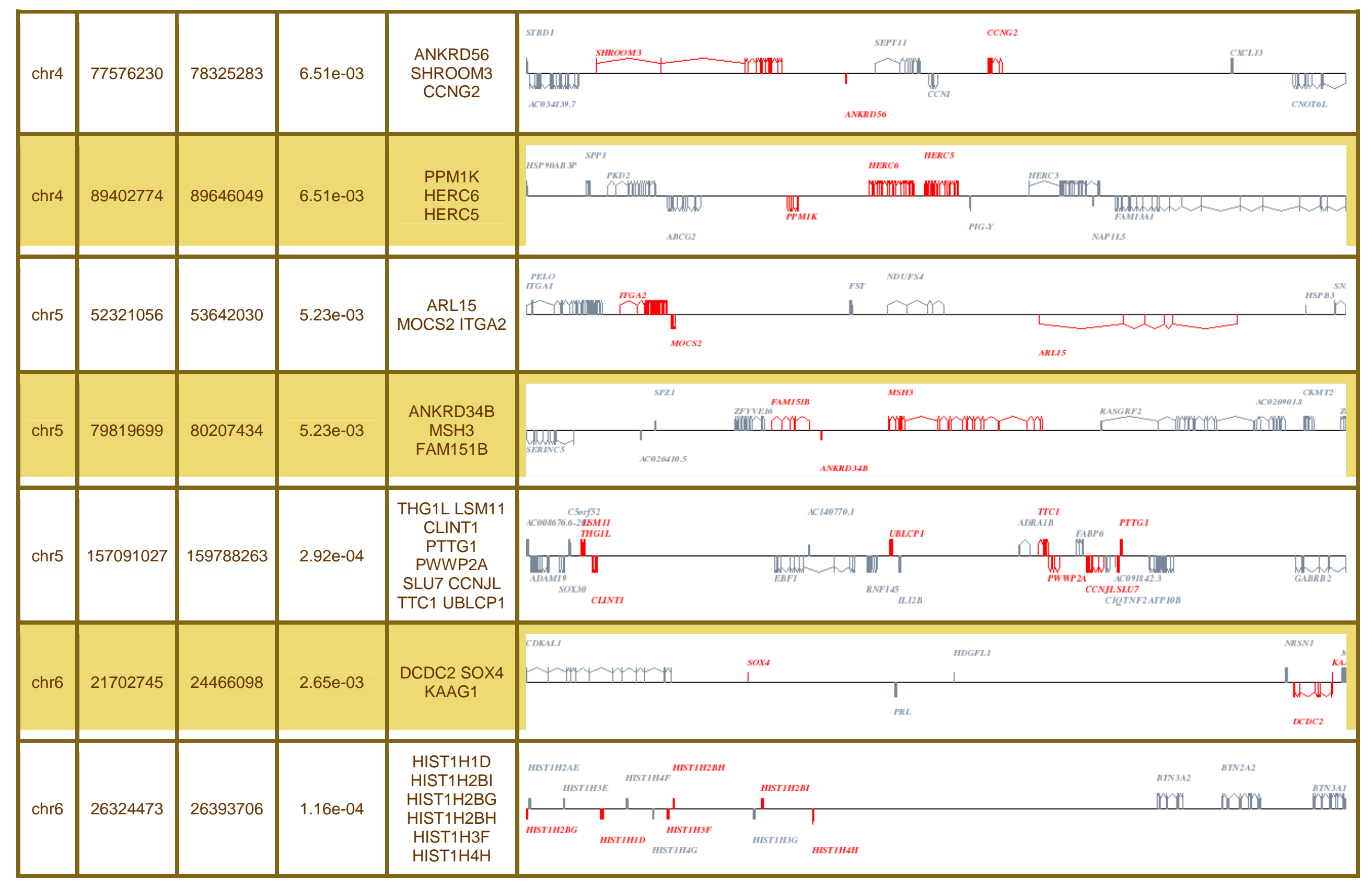




\begin{tabular}{|c|c|c|c|c|c|}
\hline chr6 & 27883286 & 27907284 & $1.16 \mathrm{e}-04$ & $\begin{array}{l}\text { HIST1H2AJ } \\
\text { HIST1H4K } \\
\text { HIST1H2BL } \\
\text { HIST1H4J }\end{array}$ & 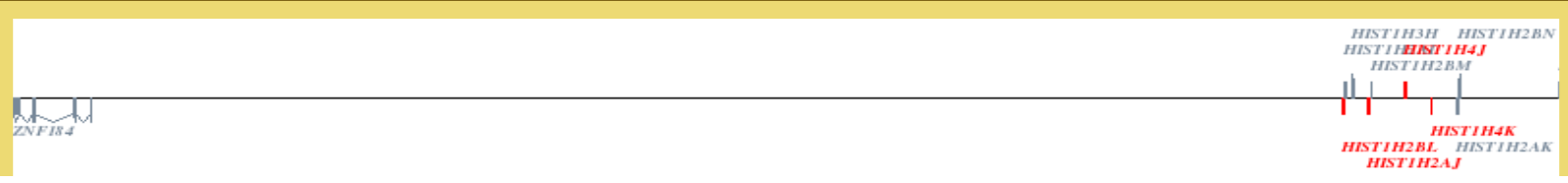 \\
\hline chr7 & 99743445 & 99913597 & $2.62 \mathrm{e}-03$ & $\begin{array}{l}\text { TSC22D4 } \\
\text { MEPCE } \\
\text { AC005071.2 } \\
\text { PILRA }\end{array}$ & 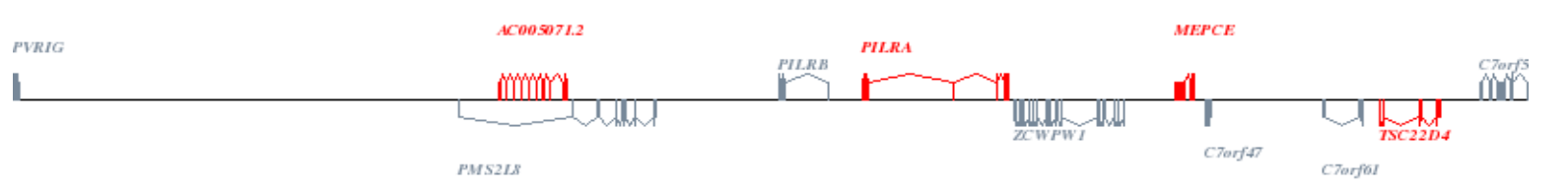 \\
\hline chr7 & 100239022 & 100519578 & $2.62 \mathrm{e}-03$ & $\begin{array}{c}\text { TRIM56 ACHE } \\
\text { MUC3A } \\
\text { EPHB4 }\end{array}$ & 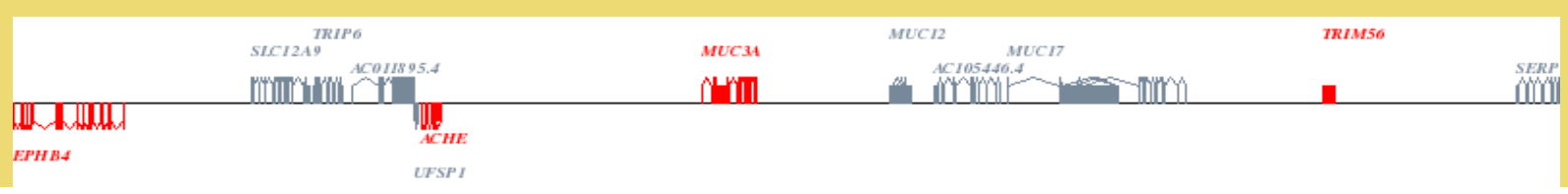 \\
\hline chr8 & 143542562 & 143813856 & $2.36 \mathrm{e}-03$ & $\begin{array}{l}\text { BAl1 PSCA } \\
\text { C8orf55 }\end{array}$ & 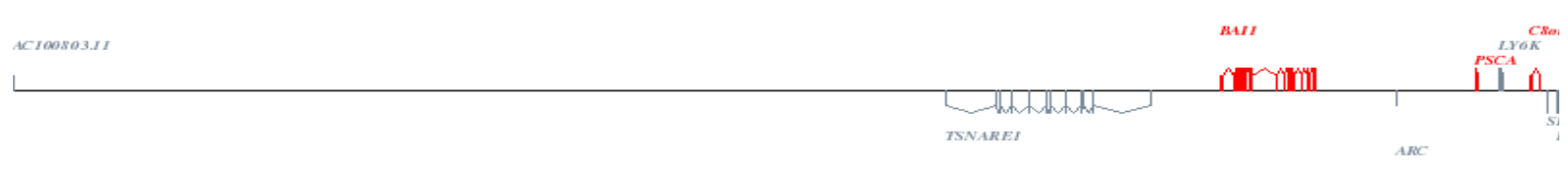 \\
\hline chr9 & 94778360 & 94915207 & $5.08 \mathrm{e}-03$ & $\begin{array}{c}\text { FGD3 SUSD3 } \\
\text { C9orf89 }\end{array}$ & 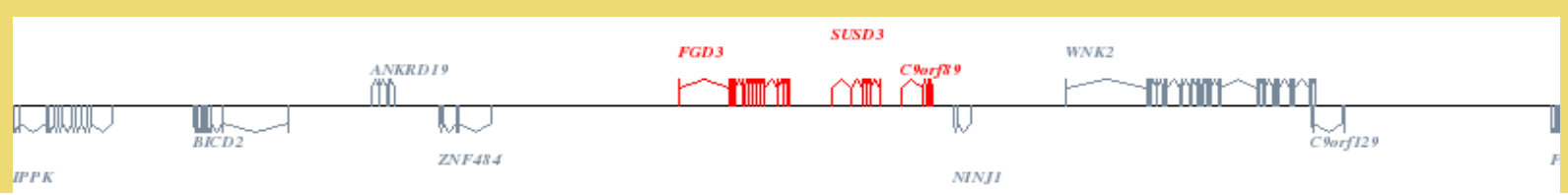 \\
\hline chr9 & 129414504 & 129537384 & $5.08 \mathrm{e}-03$ & $\begin{array}{l}\text { TOR2A } \\
\text { STXBP1 } \\
\text { PTRH1 }\end{array}$ & IRSAM \\
\hline chr9 & 138456031 & 138701630 & $5.08 \mathrm{e}-03$ & $\begin{array}{l}\text { EGFL7 } \\
\text { SEC16A } \\
\text { AGPAT2 }\end{array}$ & PMAFCA \\
\hline
\end{tabular}




\section{Figure S2. Top ranked networks identified by IPA from ACSL4-overexpressing cells.}

Networks are displayed graphically as nodes (genes/gene products) and edges (biological relationships between the nodes). Intensity of the node color indicates the degree of regulation (red: upregulation, green: downregulation, white: not differentially expressed but related to this network).

A: Network for DNA Replication, Recombination, and Repair, Gene Expression, Cancer (score: 44).

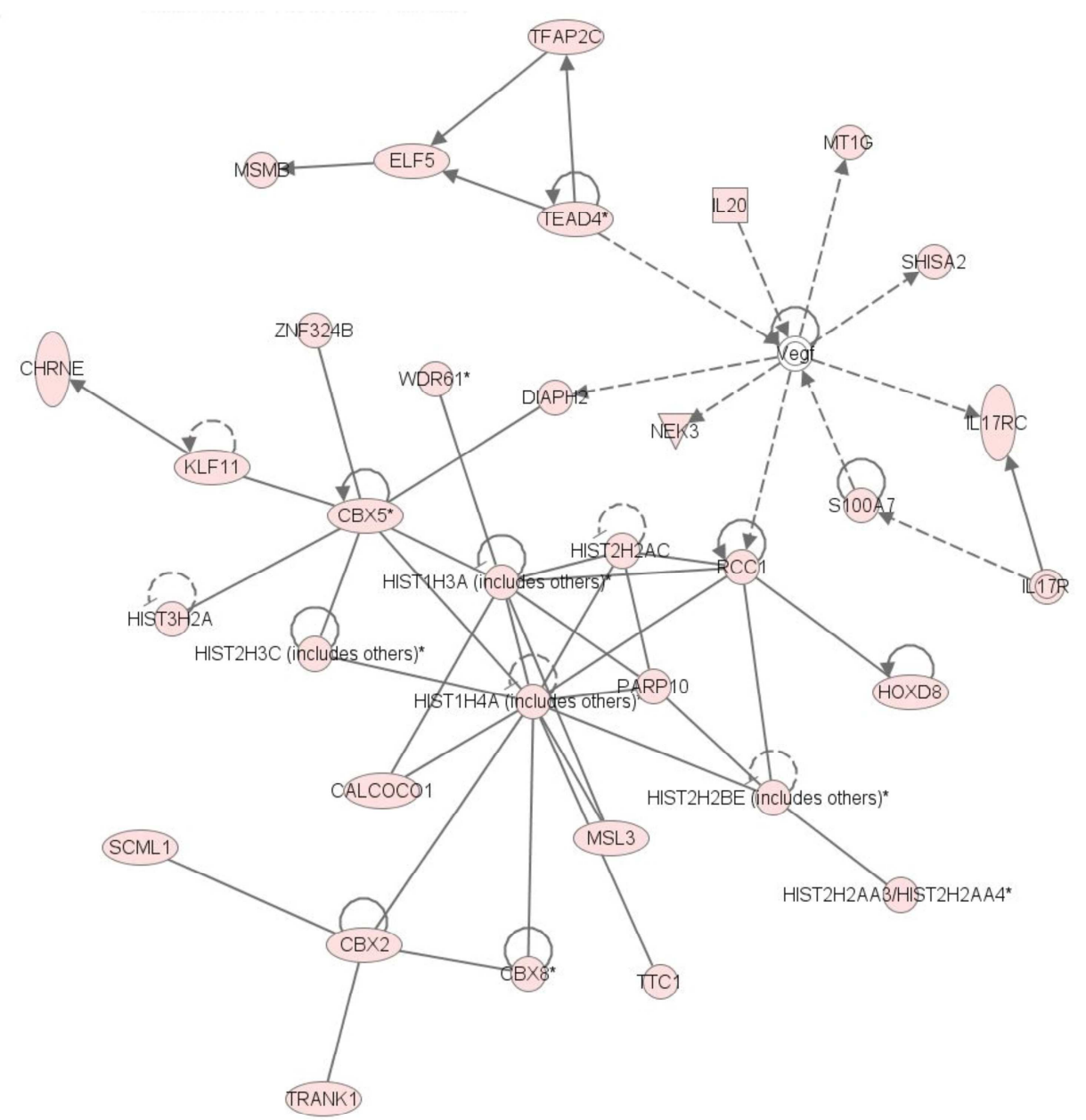

B: Network for Carbohydrate Metabolism, Small Molecule Biochemistry, Post-Translational Modification (score: 43).

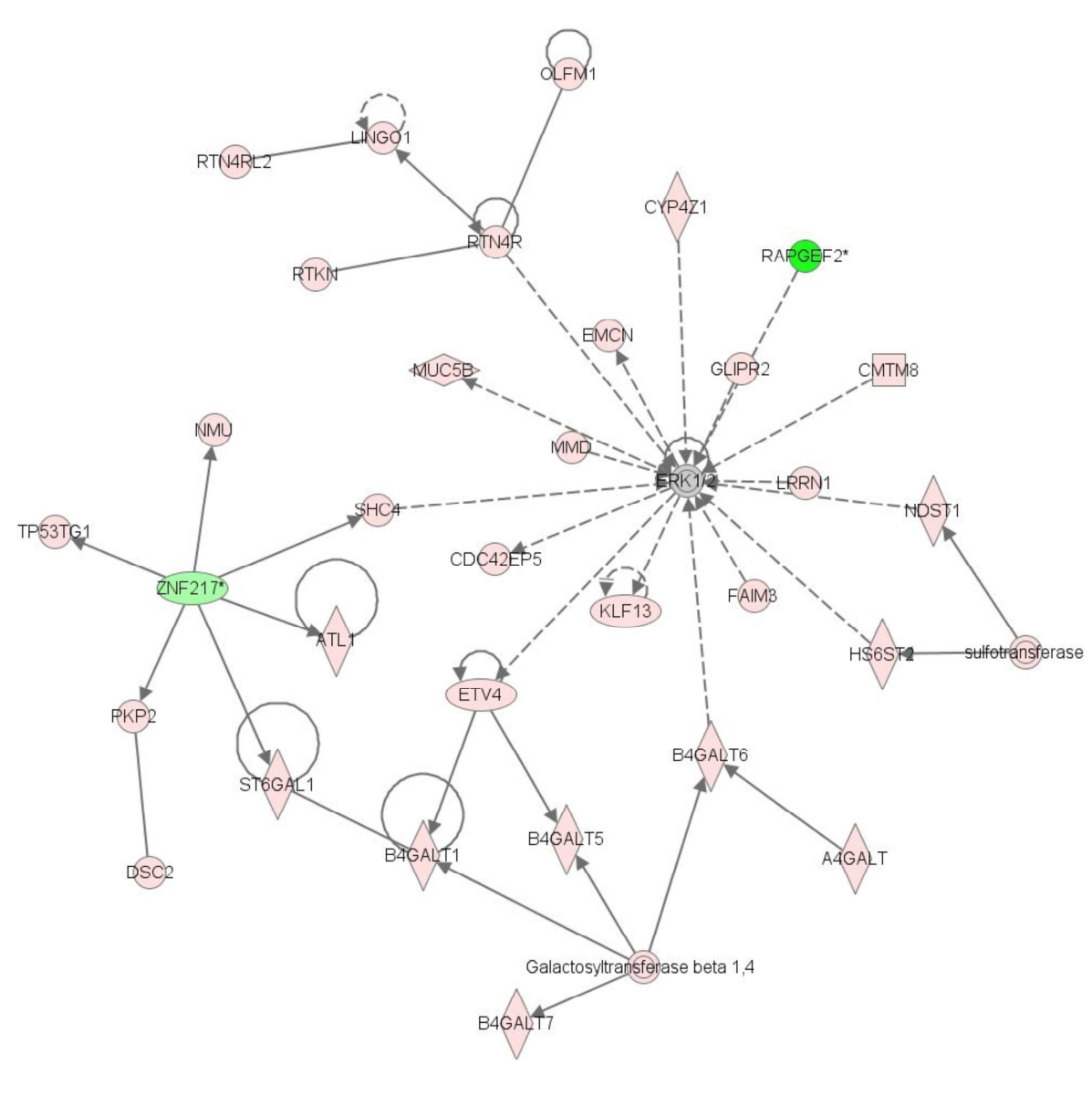


C: Network for Molecular Transport, Hereditary Disorder, Neurological Disease (score: 35 ).

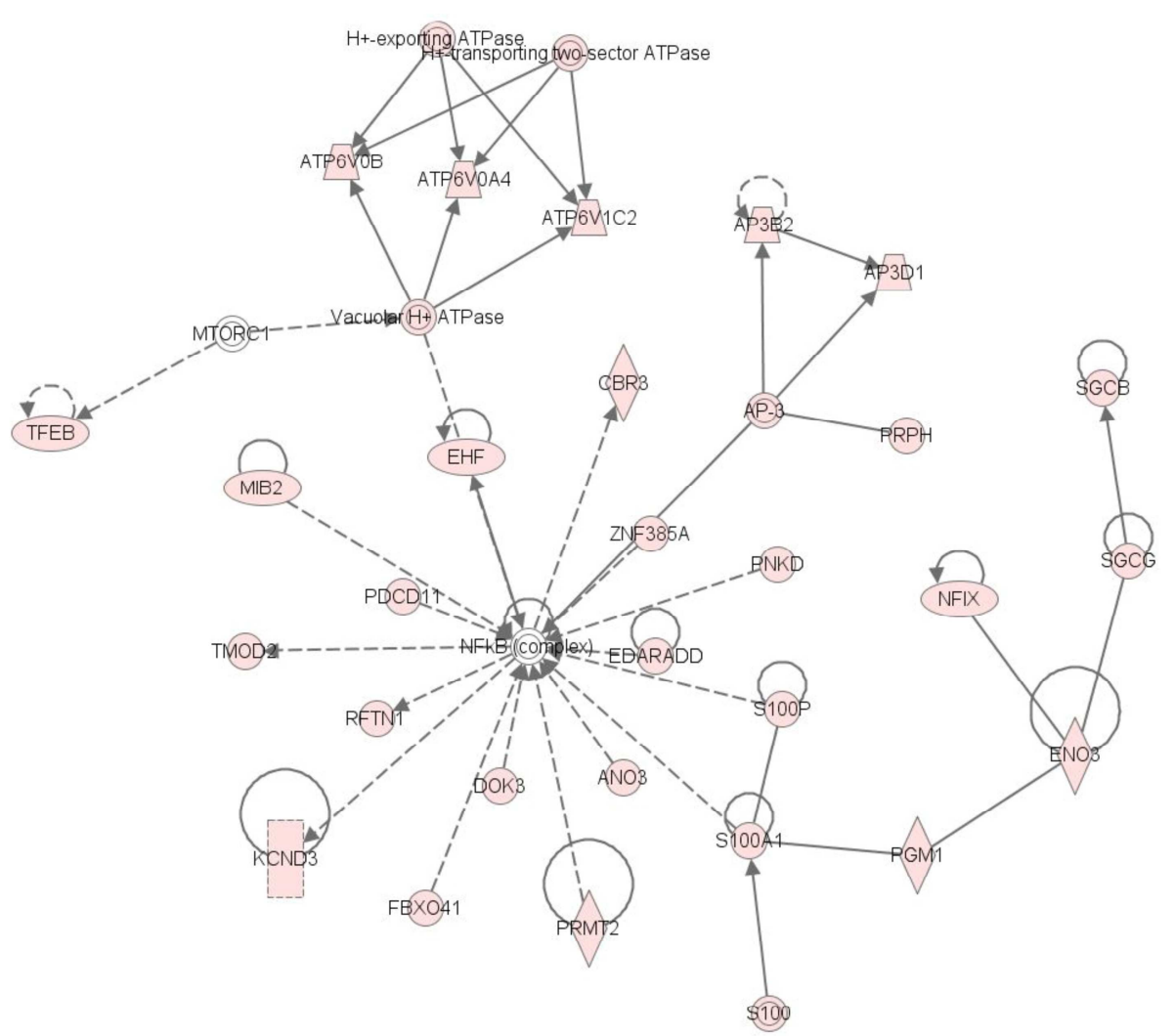

D: Network for Cellular Development, Embryonic Development, Developmental Disorder (score: 31 ).

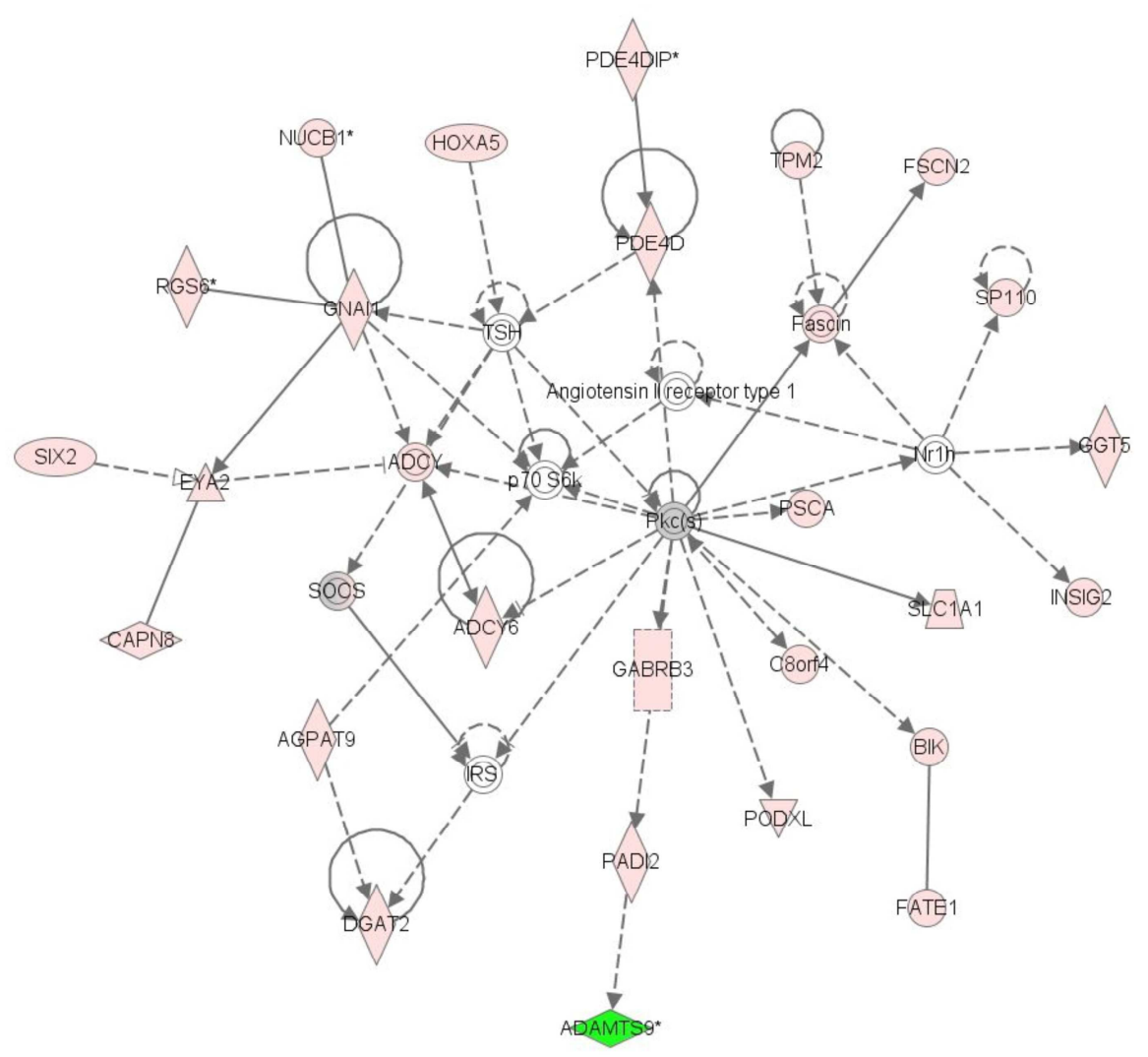


E: Network for Cardiovascular Disease, Cancer, Dermatological Diseases and Conditions (score: 31 ).

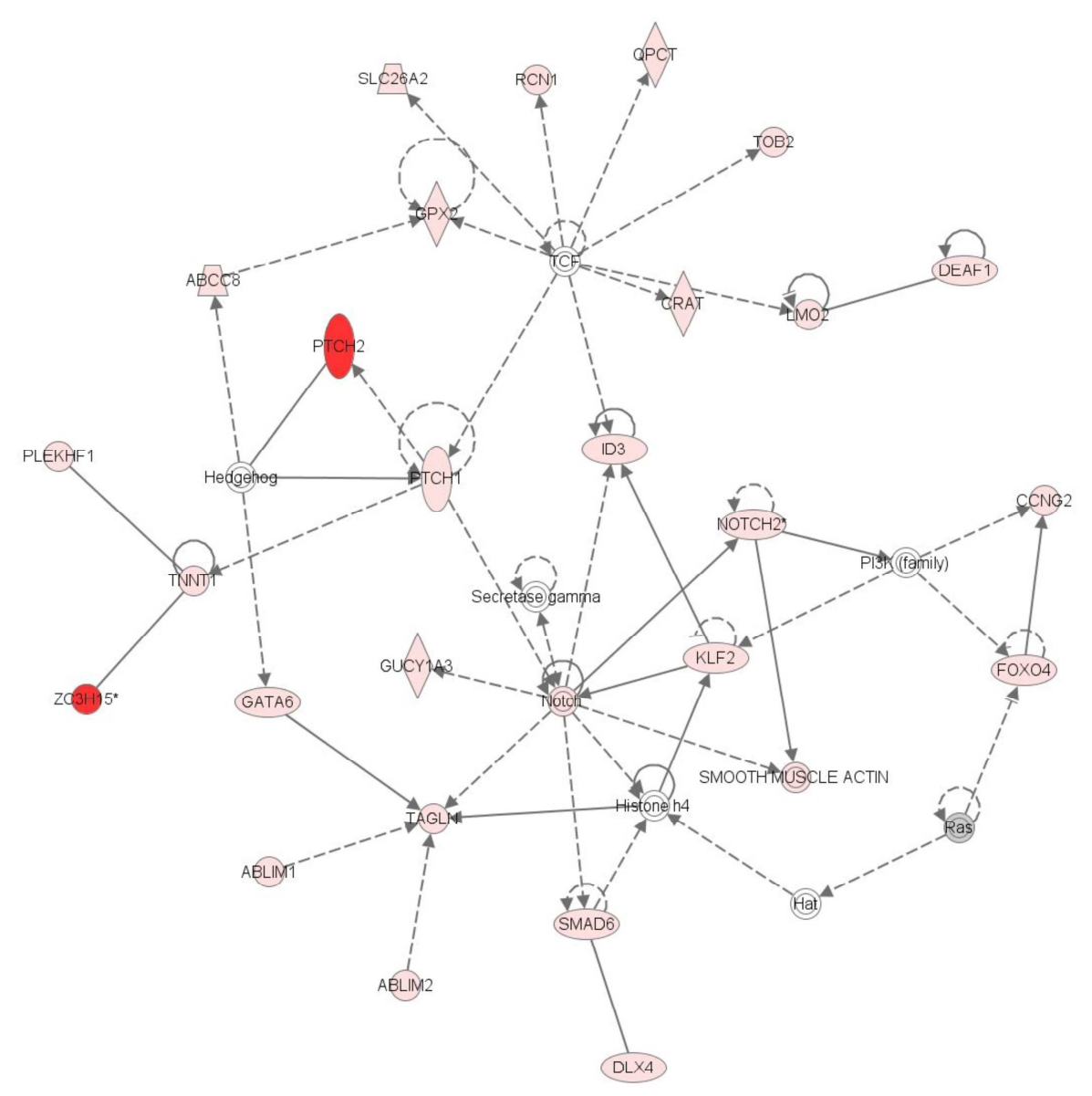

F: Network for Carbohydrate Metabolism, Tissue Morphology, Ophthalmic Disease (score: 31 ).

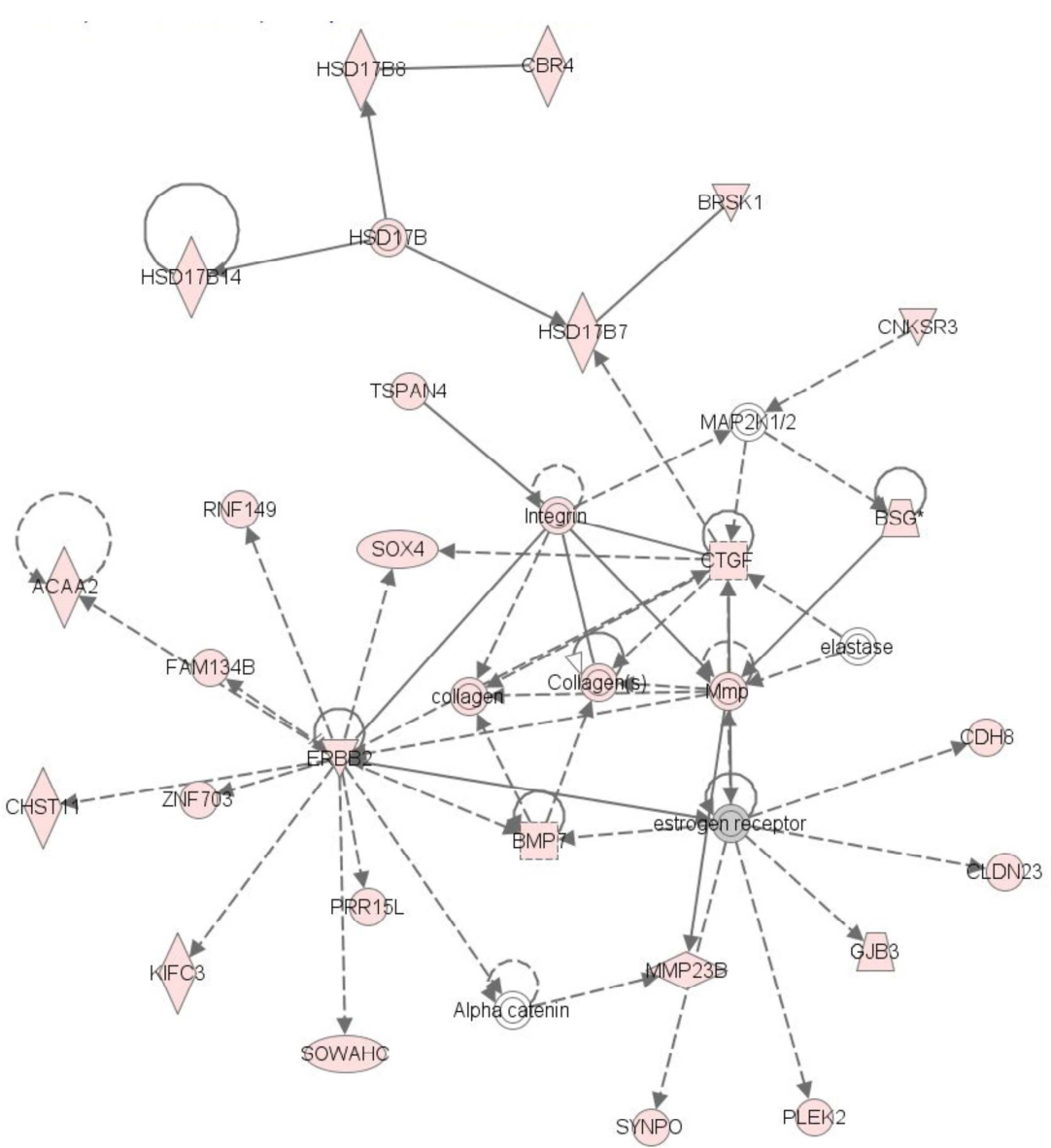


G: Network for Cell Morphology, Hair and Skin Development and Function, Organ Morphology (score: 29).

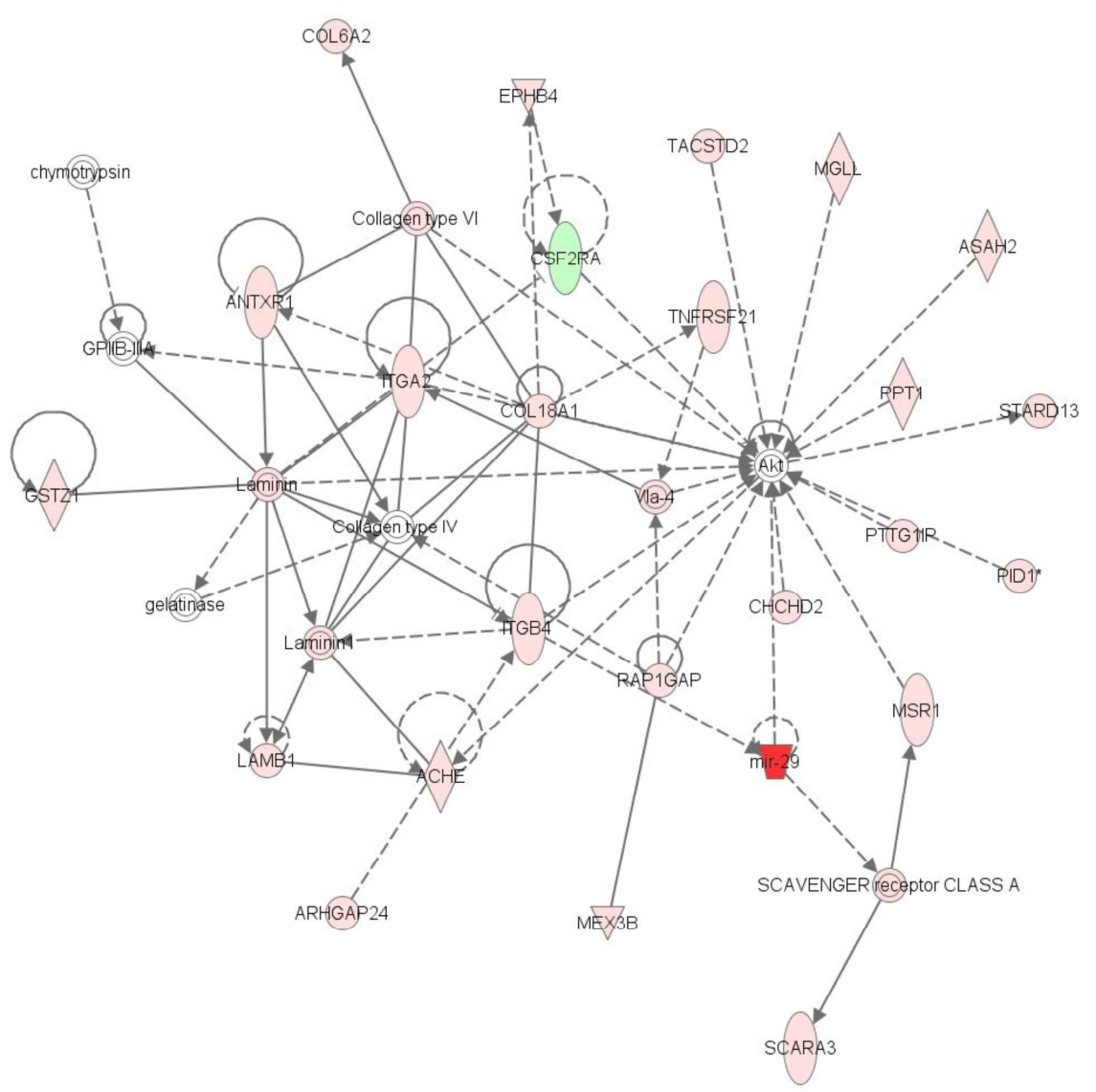

H: Network for Cell Morphology, Cellular Compromise, Lipid Metabolism (score: 29).

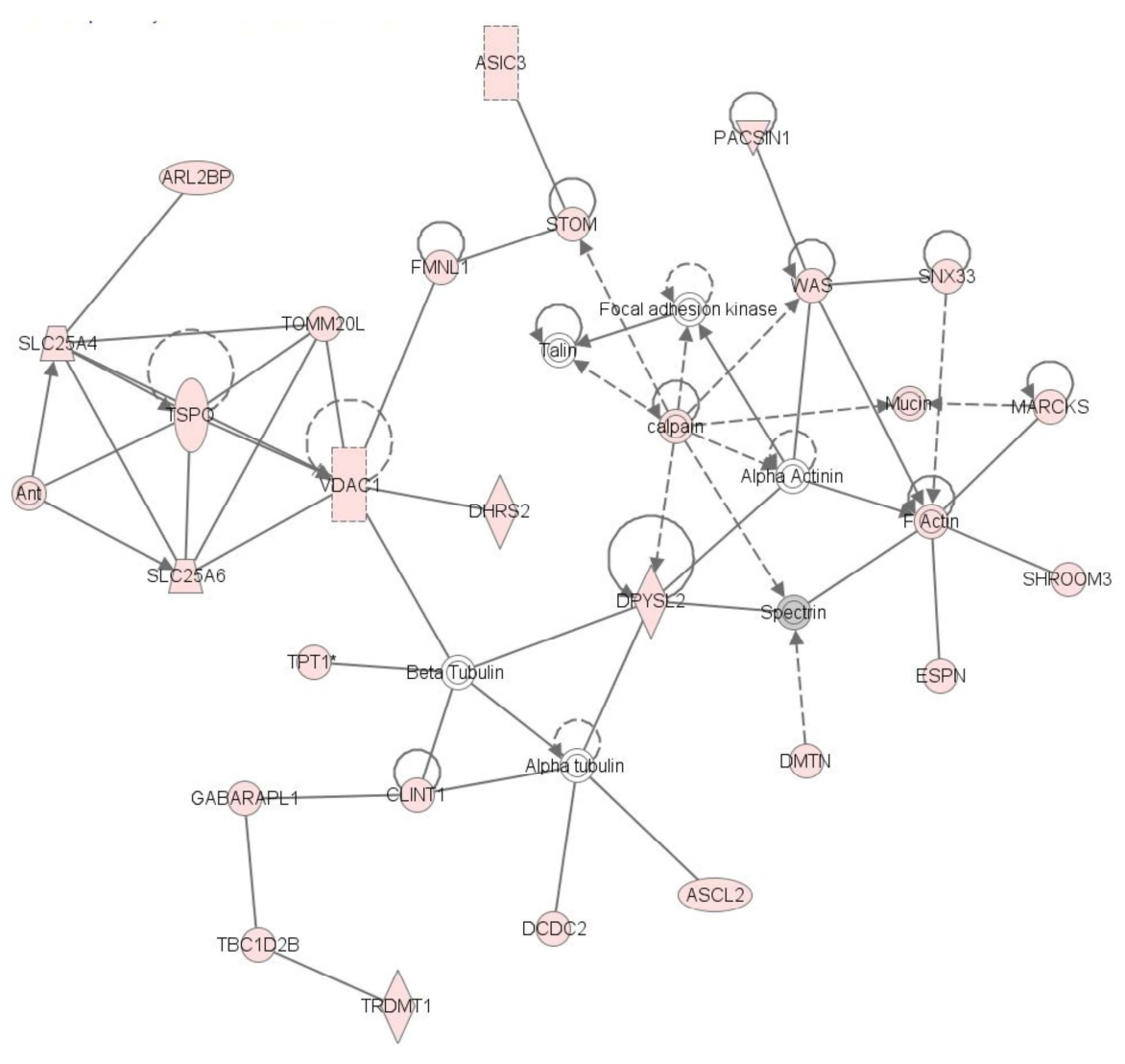


I: Network for Cancer, Dermatological Diseases and Conditions, Hematological Disease (score: 29).

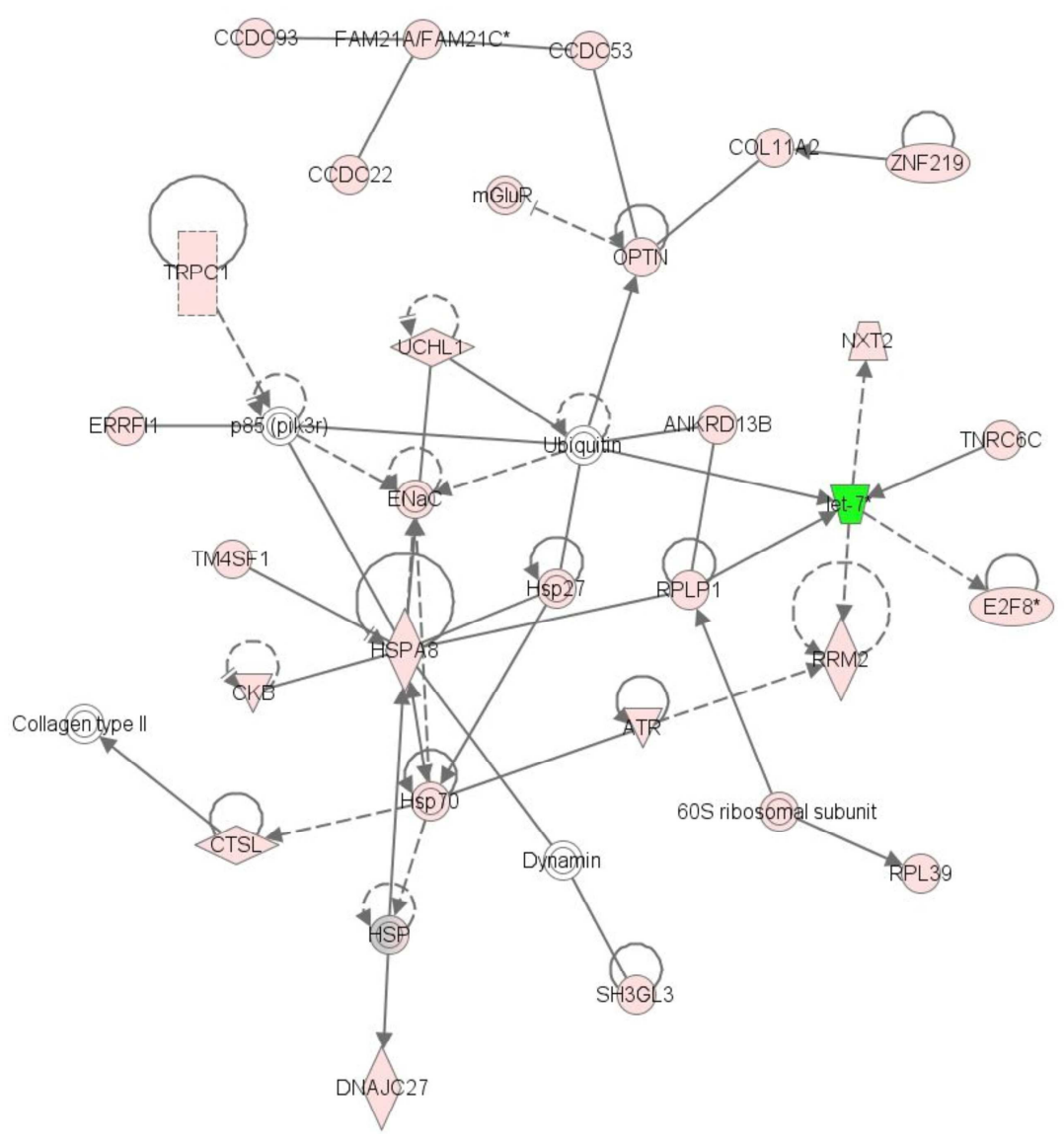

J: Network for Endocrine System Development and Function, Small Molecule Biochemistry, Developmental Disorder (score: 29).

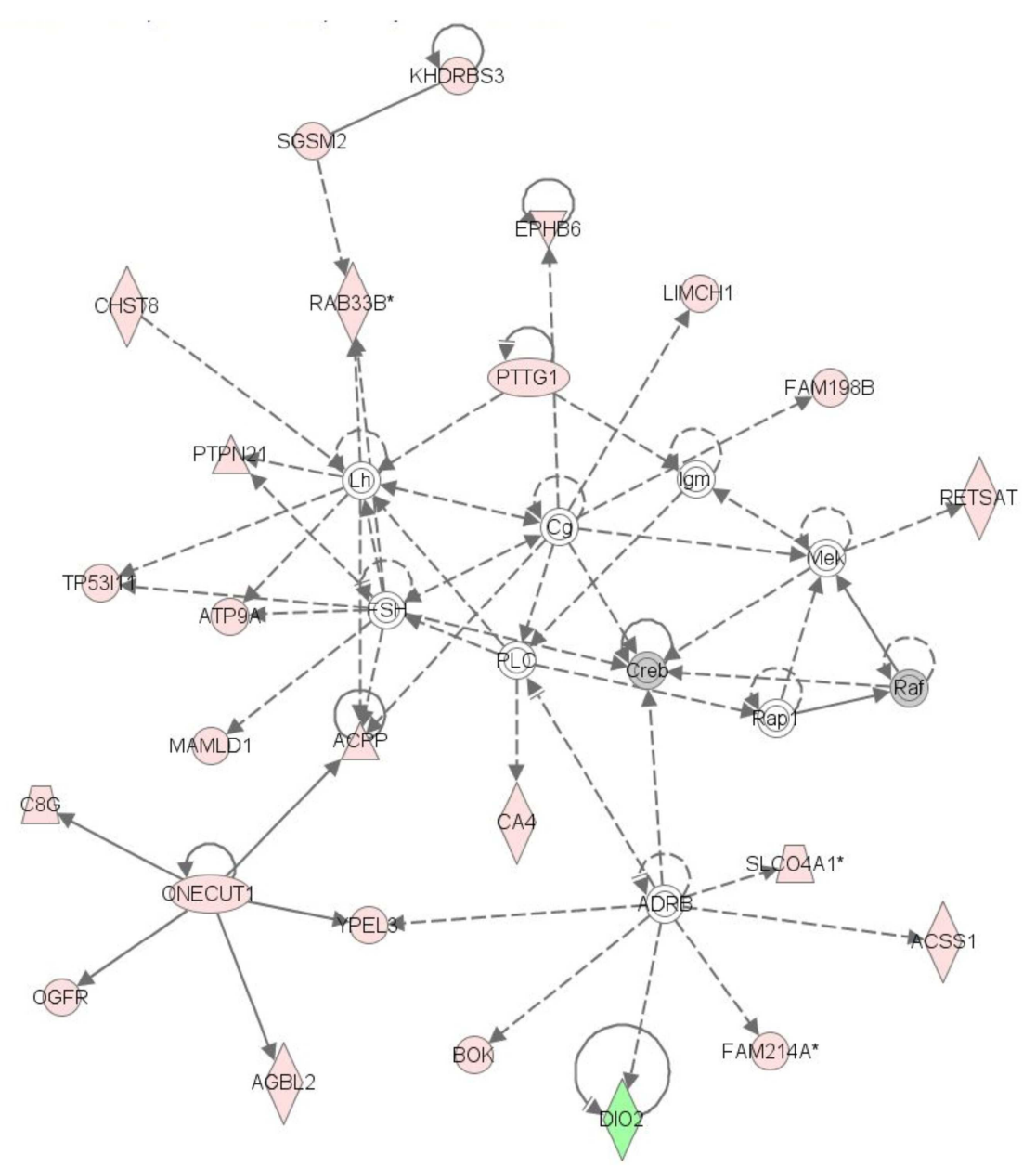

